\title{
Aerosol impacts on California winter clouds and precipitation during CalWater 2011: local pollution versus long-range transported dust
}

\author{
J. Fan ${ }^{1}$, L. R. Leung ${ }^{1}$, P. J. DeMott ${ }^{2}$, J. M. Comstock ${ }^{1}$, B. Singh ${ }^{1}$, D. Rosenfeld ${ }^{3}$, J. M. Tomlinson ${ }^{1}$, A. White ${ }^{4}$, K. \\ A. Prather ${ }^{5}$, P. Minnis ${ }^{6}$, J. K. Ayers ${ }^{7}$, and Q. Min $^{8}$ \\ ${ }^{1}$ Climate Physics, Pacific Northwest National Laboratory, Richland, WA 99352, USA \\ ${ }^{2}$ Department of Atmospheric Science, Colorado State University, Fort Collins, CO, 80523, USA \\ ${ }^{3}$ Institute of Earth Sciences, The Hebrew University of Jerusalem, Jerusalem, 91904 Israel \\ ${ }^{4}$ NOAA/ESRL, R/PSD2, 325 Broadway, Boulder, CO 80305, USA \\ ${ }^{5}$ Department of Chemistry and Biochemistry, Scripps Institution of Oceanography, University of California, San Diego, La \\ Jolla, CA 92093-0314, USA \\ ${ }^{6}$ NASA Langley Research Center (LaRC), Hampton, VA, USA \\ ${ }^{7}$ Science Systems and Applications Incorporated, Hampton, VA, USA \\ ${ }^{8}$ Atmospheric Sciences Research Center, State University of New York at Albany, Albany, NY 12203, USA
}

Correspondence to: J. Fan (jiwen.fan@pnnl.gov)

Received: 18 June 2013 - Published in Atmos. Chem. Phys. Discuss.: 26 July 2013

Revised: 21 October 2013 - Accepted: 26 November 2013 - Published: 3 January 2014

\begin{abstract}
Mineral dust aerosols often observed over California in winter and spring, associated with long-range transport from Asia and the Sahara, have been linked to enhanced precipitation based on observations. Local anthropogenic pollution, on the other hand, was shown in previous observational and modeling studies to reduce precipitation. Here we incorporate recent developments in ice nucleation parameterizations to link aerosols with ice crystal formation in a spectralbin cloud microphysical model coupled with the Weather Research and Forecasting (WRF) model in order to examine the relative and combined impacts of dust and local pollution particles on cloud properties and precipitation type and intensity. Simulations are carried out for two cloud cases (from the CalWater 2011 field campaign) with contrasting meteorology and cloud dynamics that occurred on 16 February (FEB16) and 2 March (MAR02). In both cases, observations show the presence of dust and biological particles in a relative pristine environment. The simulated cloud microphysical properties and precipitation show reasonable agreement with aircraft and surface measurements. Model sensitivity experiments indicate that in the pristine environment, the dust and biological aerosol layers increase the accumu-
\end{abstract}

lated precipitation by $10-20 \%$ from the Central Valley to the Sierra Nevada for both FEB16 and MAR02 due to a $\sim 40 \%$ increase in snow formation, validating the observational hypothesis. Model results show that local pollution increases precipitation over the windward slope of the mountains by a few percent due to increased snow formation when dust is present, but reduces precipitation by $5-8 \%$ if dust is removed on FEB16. The effects of local pollution on cloud microphysics and precipitation strongly depend on meteorology, including cloud dynamics and the strength of the Sierra Barrier Jet. This study further underscores the importance of the interactions between local pollution, dust, and environmental conditions for assessing aerosol effects on cold-season precipitation in California.

\section{Introduction}

Precipitation is an important process that regulates atmospheric moisture, heat budgets, and local hydrological cycles. Affected by many factors such as large-scale dynamics, solar heating, and aerosol particles (Shen et al., 2010; Rosenfeld 
et al., 2008), precipitation has always been very challenging to predict. Snow in the Sierra Nevada is California's largest source of fresh water. Understanding the factors contributing to precipitation and snowpack formation has important implications for predicting the hydrology and local climate of the region. This has motivated a series of CalWater field campaigns, carried out since 2009 , to improve understanding of processes influencing precipitation and water supply in California.

Aerosols in the atmosphere can act as cloud condensation nuclei $(\mathrm{CCN})$ or ice nucleating particles (INP) to modify cloud microphysical processes and potentially change the location, intensity, and type of precipitation (Tao et al., 2012). Studies have shown that an increase in anthropogenic pollution can result in a reduction of precipitation from orographic clouds due to slow conversion of cloud droplets into raindrops (Lynn et al., 2007; Rosenfeld and Givati, 2006; Jirak and Cotton, 2006) and also reduce the snowfall rate of orographic clouds by reducing riming efficiency (Lowenthal et al., 2011; Saleeby et al., 2009; Rosenfeld et al., 2008; Borys et al., 2003). Suppression of orographic precipitation by anthropogenic aerosols can be a significant problem along the US West Coast, where precipitation over the mountains is a major water source for the semi-arid region. Pristine air that comes from the Pacific Ocean becomes polluted over the densely populated coastal plains and the central Sierra Valley before ascending over the Sierra Nevada downwind. The westerly storm track during the cold season brings in episodic bands of high water vapor concentrations, also known as "atmospheric rivers" (ARs) that provide the potential for heavy precipitation and flooding. How pollution and clouds interact under AR conditions is not yet clear and is investigated in this study.

Besides the local pollution from the populated coastal plains and the Central Valley, long-range transport of Asian dust has been shown to impact western North American air quality (VanCuren and Cahill, 2002). It is known that dust particles can be transported intercontinentally on the timescale of days (Uno et al., 2009). Past observational studies also indicated that the long-range transported dust could act as effective ice nuclei and impact cloud properties and precipitation in the western and central US (Sassen, 2002; Pratt et al., 2009). Recent analysis of observational data from the CalWater Early Start campaign (22 February to 11 March 2009) and CalWater2011 shows that dust and biological aerosols transported from northern Asia and the Sahara were present in glaciated high-altitude clouds in the Sierra Nevada coincident with elevated INP concentrations and iceinduced precipitation (Ault et al., 2011; Creamean et al., 2013).

Mineral dust particles may act as cloud condensation nuclei $(\mathrm{CCN})$ or ice nucleating particles (INP) (e.g., Karydis et al., 2011; Yamashita et al., 2011; Connolly et al., 2009; Marcolli et al., 2007). The impact of dust through its role as $\mathrm{CCN}$ versus INP on precipitation from mixed-phase clouds is likely to have counteracting effects. Under a clean and moist environment, warm rain from low-level clouds alone can produce floods in the coastal mountain area (White et al., 2003). Increasing CCN could make the conversion to raindrops less efficient for the low-level clouds, and also reduce riming efficiency for the mixed-phase clouds. However, increasing INP could increase the rimed mass and enhance the Wegener-Bergeron-Findeisen (WBF) process (i.e., ice particles grow at the expense of liquid particles due to the lower saturation vapor pressure over ice compared with that over liquid at a given temperature) due to enhanced ice formation (Fan et al., 2011; Saleeby et al., 2013), and enhance precipitating ice particles such as snow. Ault et al. (2011) speculated that the increased precipitation in a dust case compared to a no-dust (conditions under which there is no longrange transported dust) case during the CalWater Early Start campaign was associated with long-range transported Asian dust particles that serve as INP and increase the riming rate. Creamean et al. (2013) further supported the hypothesis of Ault et al. (2011) by examining in situ aircraft and groundbased data. In addition, when INP are mostly absent in a cloud layer, supercooled drops can be abundant even at temperatures as cold as $-21{ }^{\circ} \mathrm{C}$ (Rosenfeld et al., 2013).

Although significant insights have been gained through observational analyses of the potential impacts of aerosols on clouds and precipitation, distinguishing the contributions of different factors including meteorology or cloud regimes and aerosol compositions and concentrations is difficult. This challenge, however, can be greatly facilitated by the combined use of observational data and theoretical modeling to examine the contribution of mineral dust particles acting as INP on precipitation to test the hypothesis proposed by Ault et al. (2011) and Creamean et al. (2013). More specifically, modeling studies are essential for qualitatively and quantitatively understanding the relative impacts of local anthropogenic pollution and long-range transported dust on cloud properties and precipitation.

To examine the effects of mineral dust through its selective role as INP, ice nucleation parameterizations have to be linked with aerosol properties such as number concentrations, surface area, etc. Most ice nucleation parameterizations used in cloud and climate models are formulated as empirical functions of only temperature and/or supersaturation (e.g., Fletcher, 1962; Young, 1974; Meyers et al., 1992; Cotton et al., 1986), which cannot be used to examine the effects of aerosols that serve as INP. In recent years, new parameterizations (e.g., DeMott et al., 2010; Niemand et al., 2012; DeMott et al., 2013; Phillips et al., 2013) or modifications of existing parameterizations (e.g., van den Heever et al., 2006; Muhlbauer and Lohmann, 2009) have been made to link aerosols with ice nucleation. These recent developments allow us to investigate the INP effects of aerosols.

In this study, we incorporate recent developments in ice nucleation parameterizations to link ice nucleating aerosols with ice crystal formation in a spectral-bin microphysical 
(a) FEB16

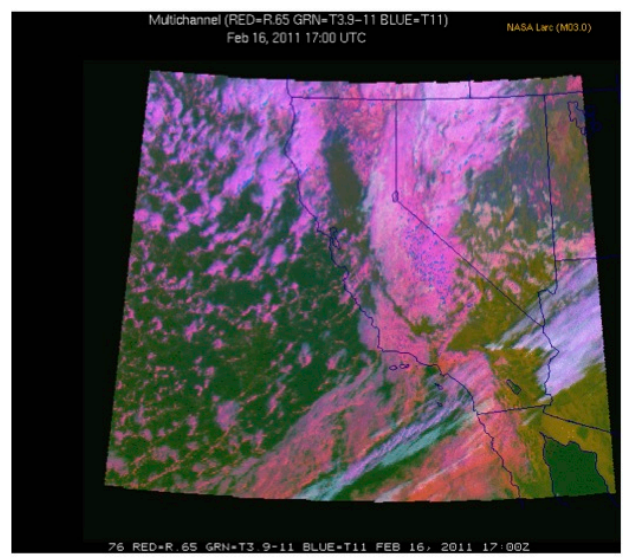

17:00 UTC on Feb. 16 (b) MAR02

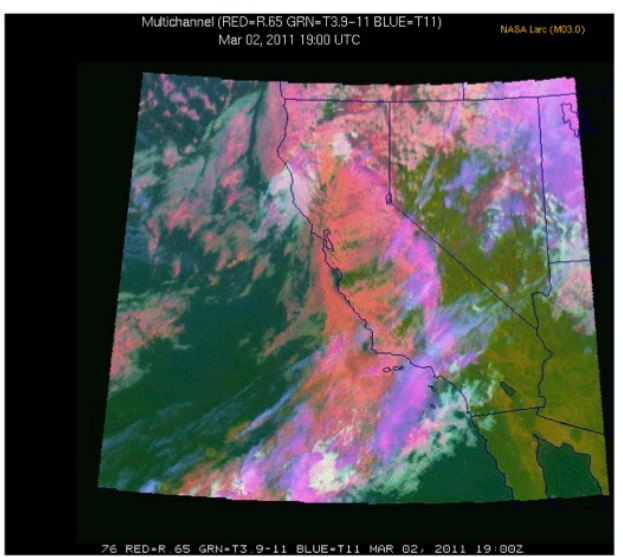

19:00 UTC on Mar. 02

Fig. 1. Multi-channel RGB images from GOES-11 for (a) FEB16 and (b) MAR02. Images are from the VISST Cloud Product. In the figures, red was produced using the visible $(0.65 \mu \mathrm{m})$ reflectance (R_65). Green was produced using the differences between the 3.9- $\mu \mathrm{m}$ and 11 $\mu \mathrm{m}$ brightness temperatures (T3.9-11). Blue was produced using the 11- $\mu \mathrm{m}$ brightness temperature (T11). This color combination allows discrimination between low, middle and high clouds. The peach-colored areas indicate low clouds, like stratus; the bright pink to white areas indicate high ice clouds like cirrus; and the red areas indicate mid-level clouds. There are some dark pink, almost red areas in Nevada and over the Sierra Nevada, which are snow-covered.

model (SBM) (Khain et al., 2004; Khain and Lynn, 2009; Fan et al., 2012a) coupled with the Weather Research and Forecasting (WRF) model (Skamarock et al., 2005). We employ the model to simulate two mixed-phase cloud cases from the CalWater 2011 field campaign in which mineral dust and biological particles were observed entering and affecting supercooled cloud layers. We examine how mineral dust and local pollution particles can potentially affect cloud microphysical properties and precipitation type and intensity. The two cloud cases and the related observations that are used for evaluation of simulations are detailed in the following section.

\section{Observations}

The CalWater 2011 field campaign was conducted from late January to early March, centered over the California Sierra Nevada. Aerosol, meteorology, cloud physics and microphysics data were collected using ground-based measurements, in situ aircraft observations, and satellite measurements (http://www.esrl.noaa.gov/psd/calwater/). One of the major goals was to advance our understanding of how orographic precipitation is impacted by anthropogenic aerosols and long-range transported dust. Aircraft measurements were taken on board the US Department of Energy Gulfstream-1 (G-1) aircraft. During the field campaign period, dust was often identified in precipitation samples (Creamean et al., 2013). 15-16 February 2011 (referred to as "FEB16" hereinafter), was one of the dust cases in which significant precipitation was produced in the form of snow. In spite of the cold temperature (surface $T$ is lower than $0^{\circ} \mathrm{C}$ ), clouds on
15 February were confined to the lower altitudes and negligible ice was detected based on aircraft measurements. The lower-level clouds merged with the elevated cloud base over the foothills and became deeper in the afternoon of 16 February (Fig. 1a). An AR of medium strength was present in this case (Neiman et al., 2008a, b; Ault et al., 2011). ARs were identified by long and narrow plumes of integrated water vapor exceeding $2 \mathrm{~cm}$. A Sierra Barrier Jet (SBJ), as often observed during AR events (Neiman et al., 2010), was present with wind speeds of about $24 \mathrm{~m} \mathrm{~s}^{-1}$. Heavy snow $(78.7 \mathrm{~cm})$ was observed at Norden $\left(39.32^{\circ} \mathrm{N}, 120.37^{\circ} \mathrm{W}\right)$. The flight on 16 February (referred to as Flt0216) sampled very different clouds during its ascent and descent periods due to changing dynamics (Creamean et al., 2013). During the ascent period (morning of 16 February), there were distinct cloud layers, including convective clouds $(\leq 3500 \mathrm{~m})$, which were decoupled from the boundary layer containing local pollution aerosols, and mid-level orographic clouds ( 4000-6000 m). During the descent (afternoon of 16 February), the boundary layer rose higher in altitude, coupling with the convective clouds.

Another cloud case that we simulate occurred on 1-2 March 2011 (referred to as "MAR02" hereinafter). In contrast to FEB16 with the westerly flow, airflow was southeasterly and parallel to the topographic gradients (discussed more in Results) with weak orographic forcing. A southwest subtropical jet moved over California and shallow clouds developed (Fig. 1b). The AR was classified as medium strength (Neiman et al., 2008a,b), similar to FEB16, but the SBJ was stronger $\left(30 \mathrm{~m} \mathrm{~s}^{-1}\right)$ on MAR02 than on FEB16. Snow was not observed at the Sugar Pine Dam (SPD) on 1 March but 
light snow was observed on 2 March. Clouds were low, with a vertical extent of only about $3 \mathrm{~km}$. Compared to FEB16, this is a warmer case, with temperatures of about $5^{\circ} \mathrm{C}$ higher at the same altitudes. For example, cloud temperature at $3 \mathrm{~km}$ above the Central Valley was about -13 and $-8^{\circ} \mathrm{C}$ on FEB16 and MAR02, respectively. There were two flights on MAR02: at 17:00-20:00 and at 22:00-23:58 UTC. These are referred to as Flt0302a and Flt0302b, respectively. Clouds sampled in Flt0302a were mixed-phase and convective, but then became shallow and liquid-only in Flt0302b.

The aerosol and cloud properties were measured by multiple instruments mounted on G-1, including a passive cavity aerosol spectrometer probe (PCASP) sizing particles with maximum dimension $D$ between 100 to $3000 \mu \mathrm{m}$; a ultrahigh sensitivity aerosol spectrometer (UHSAS), measuring fine mode aerosol size spectra of 55-800 nm; a SPEC 2Dimensional Stereo (2DS) optical imaging probe, which sizes droplets and ice crystals between 10 and $3000 \mu \mathrm{m}$; a Droplet Measurements Technologies (DMT) cloud droplet probe (CDP, 2 to $50 \mu \mathrm{m}$ ); and a DMT cloud imaging probe (CIP, nominally sizing between 25 to $1550 \mu \mathrm{m}$ ). The SEA Model WCM-2000 Multi-Element Water Content System is designed to measure liquid-water content (LWC) and total water content (TWC). When ice is present, the ice-water content (IWC) is derived by taking the difference between TWC and LWC. The aircraft data used in this study represent the best estimates of LWC, IWC, droplet $\left(N_{w}\right)$ and ice particle number concentrations $\left(N_{i}\right)$. It should be noted that the tips on the 2DS and CIP probes were modified to minimize shattering of large ice particles (Korolov et al., 2011).

We obtained aerosol particle size distribution over the range $0.06-4 \mu \mathrm{m}$ based on a combination of UHSAS and PCASP measurements by excluding cloudy points. The UHSAS and PCASP were used for diameters less than and greater than $200 \mathrm{~nm}$, respectively. Aerosol particle number concentrations with diameter larger than $0.5 \mu \mathrm{m}$ were used as a proxy for mineral dust particle concentrations, representing an upper limit for ice-nucleating particles (DeMott et al., 2010). Using this definition on FEB16, variable dust layers were observed between $3.5-6 \mathrm{~km}$ with the highest values of $\sim 2 \mathrm{~cm}^{-3}$. On MAR02, the inferred dust concentrations were higher, with $\sim 4 \mathrm{~cm}^{-3}$ at $3-4 \mathrm{~km}$ in Flt0302a. Based on compositions measured in cloud and precipitation residues (Creamean et al., 2013), the INP on FEB16 are likely mineral dust or biological aerosols. On MAR02, because clouds were shallower and warmer, not much cold rain was detected. Still, dust and biological aerosols were found in $60-70 \%$ of precipitation residues and about $10 \%$ of cloud residues (Creamean et al., 2013). Dust aerosols can be activated as $\mathrm{CCN}$ and thereby enter clouds and precipitation. However, since ice was measured in these clouds, it is possible that some dust or mixtures of dust and biological aerosols (referred to as "bio" hereafter) interacted with some clouds that were cold enough to form ice in this case. The INP concentrations were measured in situ by the continuous-flow ice thermal diffusion chamber (CFDC) (DeMott et al., 2010; Creamean et al., 2013). The INP number concentrations measured within the dust layer as condensation and immersion freezing nuclei at (nominally) 105\% RH by the CFDC were about $5 \mathrm{~L}^{-1}$ at a processing temperature of $-30^{\circ} \mathrm{C}$ in Flt0216. These INP concentrations are about 10 times higher than the measured concentrations from the previous day (i.e., Flt0215). Note that the clouds were warmer and no ice particles were significantly detected in Flt0215. For the two flights on 2 March, the CFDC-measured INP were on the order of $1 \mathrm{~L}^{-1}$ at $-20{ }^{\circ} \mathrm{C}$ and $3-20 \mathrm{~L}^{-1}$, depending on the altitude, and at a temperature of $-30^{\circ} \mathrm{C}$.

Ground-based measurements of equivalent radar reflectivity factor $\left(Z_{\mathrm{e}}\right)$ and Doppler velocity by the NOAA (National Oceanic and Atmospheric Administration) S-band (2875 $\mathrm{MHz}$ ) precipitation profiler (S-PROF; White et al., 2000) at Sugar Pine Dam (SPD) are directly compared with the simulated quantities from a radar simulator coupled with the SBM (Fan et al., 2009). Details about the radar simulator are described in Fan et al. (2009). Surface precipitation from tipping buckets and other types of gauges deployed over the region are also compared with the modeled output.

Satellite-retrieved liquid-water path (LWP) is also compared with the model results. The observed LWP is from the satellite cloud products retrieved using the Visible Infrared Solar-Infrared Split Window Technique (VISST) algorithm (Minnis et al., 2006). The data streams are pixel-level retrievals on $\sim 0.5^{\circ}$ latitude-longitude grid. Since the satellite retrieved ice-water path (IWP) has very large uncertainties, an evaluation of IWP is not carried out.

\section{Model configuration and simulation design}

Simulations were performed using WRF version 3.1.1 developed at the National Center for Atmospheric Research (NCAR) (Skamarock et al., 2008)WRF solves the fully compressible, nonhydrostatic Euler equations formulated on the terrain following hydrostatic-pressure vertical coordinates and the Arakawa C-grid. The model uses the RungeKutta second- and third-order time integration schemes, and second- to sixth-order advection schemes in both horizontal and vertical directions (Li et al., 2008). The fifth-order advection scheme is used in this study. The monotonic technique is employed for advection of scalar and moist variables. The microphysical schemes used in the study are briefly described below.

\subsection{Spectral-bin microphysics (SBM)}

\subsubsection{The original SBM}

The spectral-bin microphysics (SBM) scheme used in this study is based on the Hebrew University Cloud Model (HUCM) described by Khain et al. (2004), Lynn and Khain (2007), and Khain et al. (2009). The microphysics 
parameterization solves a system of kinetic equations for the size distribution functions for water drops, ice crystals (plate, columnar and branch types), snow aggregates, graupel and hail, as well as CCN. Each size distribution is represented by 33 mass doubling bins, i.e., the mass of a particle $m_{k}$ in the $k$ bin is determined as $m_{k}=2 m_{k-1}$. The CCN size distribution is calculated prognostically with sinks and sources, which include advection, droplet nucleation, and $\mathrm{CCN}$ regeneration from droplet evaporation (Fan et al., 2009). Scavenging of $\mathrm{CCN}$ by precipitation is not considered. CCN activation is calculated according to the Kohler theory, i.e., CCN with radii exceeding the critical value that is calculated based on supersaturation at a grid point are activated to become droplets, and the corresponding bins of the $\mathrm{CCN}$ spectra are emptied. The original model employs the parameterization of Meyers et al. (1992) for condensation freezing and deposition nucleation, and Bigg (1953) for drop freezing (i.e., immersion and homogeneous freezing). Use of these two schemes together may provide a liberal estimate of INP concentrations in the mixed-phase regime, as it is now recognized that CFDC measurements, which were the basis of the Meyers et al. (1992) parameterization, most likely account for immersion freezing nucleation (DeMott et al., 2011; Tobo et al., 2012); but homogeneous freezing of aerosol particles is not included in these schemes. More details about the microphysical processes included in the original SBM are provided in Khain et al. (2004) and Fan et al. (2009).

Following Fan et al. (2012a), this study also employs FastSBM (Khain et al., 2009, 2010), in which ice crystal and snow (aggregates) in the full SBM are calculated on one size distribution with separation at $150 \mu \mathrm{m}$ (referred to as low-density ice), and graupel and hail in the full version are grouped as high-density ice, represented by one size distribution without separation. No changes in the microphysical processes are made compared to the full SBM. The fast version was able to produce cloud microphysical and dynamical structure as well as precipitation similarly to the full SBM (Khain et al., 2009).

\subsubsection{Modifications of the SBM for this study}

As discussed in Sect. 1, the ice nucleation parameterizations of Meyers et al. (1992) and Bigg (1953) employed in the original SBM do not connect aerosols with ice nucleation. To examine the effects of mineral dust (or a mixture of dust and biological aerosols with nucleating properties assumed to be similar to mineral dust) acting as INP, we modified the SBM to incorporate new ice nucleation parameterizations in which ice crystal formation is connected with aerosols. An additional prognostic variable for INP concentration was added to represent the sinks and sources of INP. We implemented the parameterization of DeMott et al. (2013) in the SBM to connect with the prognostic ice nucleating aerosols. This parameterization specifically connects ice nucleation by full mineral dust size distribution with mineral dust particle concentrations at sizes larger than $0.5 \mu \mathrm{m}$ (i.e., all aerosols $>0.5 \mu \mathrm{m}$ in this study). The parameterization is an update of that of DeMott et al. (2010), which was found to underestimate INP number concentrations in direct samplings of Saharan and Asian dust in both field and laboratory studies. The implementation uses independent exponential and power law dependencies of INP concentrations on temperature and aerosol concentrations, as suggested first by Tobo et al. (2013), in the form $N_{\text {INP }}$, $T_{k}=(\mathrm{CF})\left(n_{a>0.5 \mu \mathrm{m}}\right)^{\left(\alpha\left(273.16-T_{k}\right)+\beta\right)} \exp \left(\gamma\left(273.16-T_{k}\right)+\delta\right)$ (DeMott et al., 2013). CF is an instrumental correction factor with a value of 3 . Coefficients $\alpha, \beta$. $\Upsilon$, and $\delta$ are $0.0000594,1.25,0.46$, and -11.6 , respectively, for mineral dust particles (DeMott et al., 2013). $T_{k}$ is temperature in kelvin, and $\mathrm{N}_{a>0.5 \mu m}$ represents aerosol concentrations (at standard temperature and pressure) with diameters larger than $0.5 \mu \mathrm{m}$ and so $N_{\mathrm{INP}, T_{k}}$ is also referenced to standard temperature $(273 \mathrm{~K})$ and pressure $(1013.5 \mathrm{mb})$ conditions. With this parameterization, the frozen fractions are about $2.9 \times 10^{-4}$ and $2.8 \times 10^{-2}$ for a dust concentration of $1 \mathrm{~cm}^{-3}$ at temperatures of -20 and $-30^{\circ} \mathrm{C}$, respectively. For contact freezing, we adopt the implementation of Muhlbauer and Lohmann (2009) for the parameterizations described in Cotton et al. (1986) and Young (1974) to connect with INP. Therefore, besides horizontal and vertical advection, the INP sink terms are the immersion and contact freezing as described above, and the source terms are the initial and boundary conditions that are described in Sect. 3.2 for the case setup. Since INP number concentrations predicted by the DeMott et al. (2013) parameterization reference the number concentrations of aerosol particles larger than $0.5 \mu \mathrm{m}$, we represent dust with a single prognostic parameter in this study.

In this study, we implemented the parameterization of DeMott et al., 2013 for immersion freezing, that is, a preexisting liquid particle (droplet or drop) is consumed for each formed ice crystal determined by the parameterization (at the same time, an ice nucleus is removed from the INP category). Over the size spectrum of water drops, the largest drops freeze first, and then the smaller ones freeze when ice nucleation occurs. An upper limit of ice particle concentration was applied after nucleation to prevent excessive nucleation, i.e., the total ice particle concentration can not exceed the initial INP concentration set at a specific grid. With the prognostic INP and the upper limit constraint, we are able to simulate ice particle concentrations reasonably well. We do not include a parameterization for deposition nucleation in the simulations performed. Note that deposition nucleation of mineral dust is not supported, except for the largest supermicron particles, by laboratory studies in mixed-phase cloud conditions (DeMott et al., 2011; Hoose and Moehler, 2012; Sullivan et al., 2010; Tobo et al., 2012). Nor is it supported by field observations (e.g., Stith et al., 2009; Field et al., 2012). In a test using the deposition parameterization of Meyers et al. (1992) to predict INP concentrations (and connected 
(a) FEB16

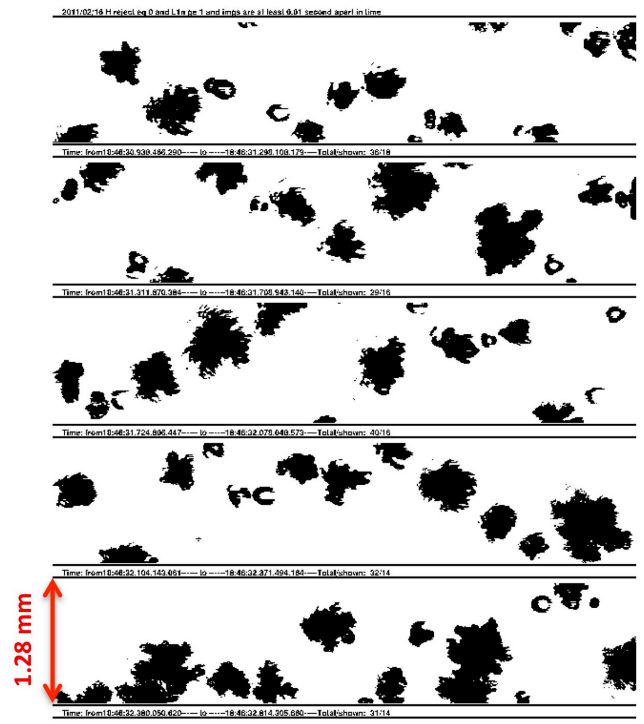

(b) MAR02

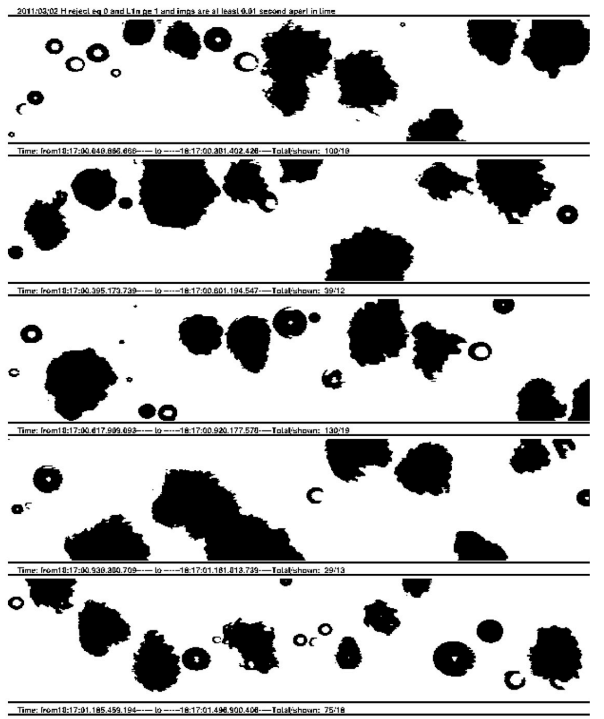

Fig. 2. Images of 2DS for cloud hydrometeors in (a) FEB16 and (b) MAR02 at 18:46:30 UTC on 16 February and 18:17:00 UTC on 2 March, respectively.

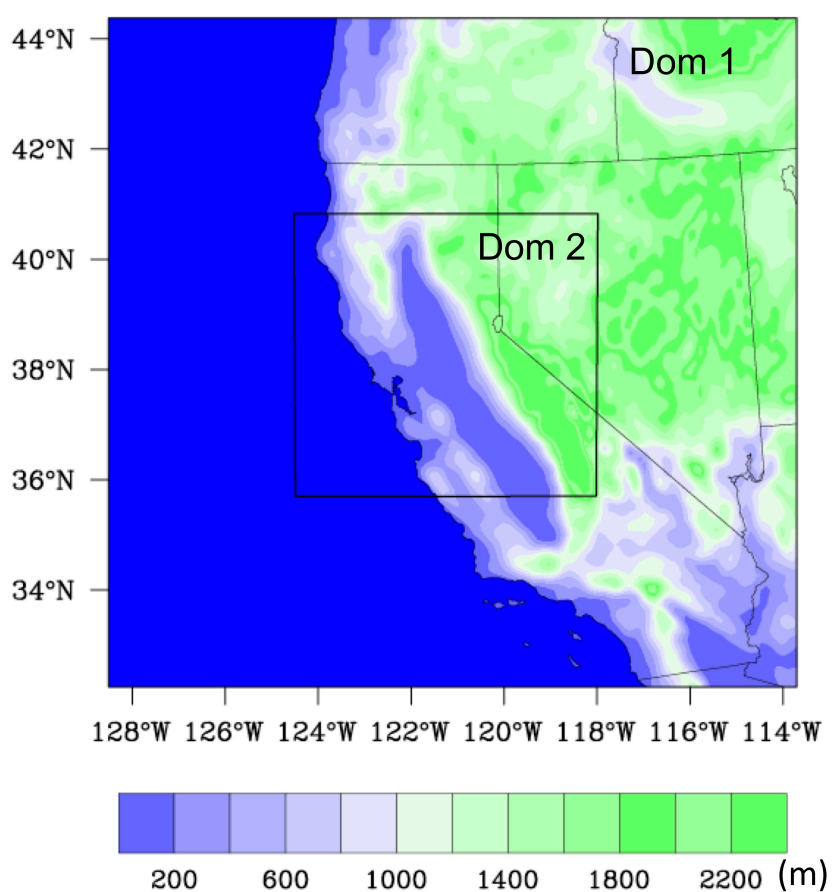

Fig. 3. The model domains: domain 1 and domain 2 . The color contour denotes the terrain height. Blue denotes the ocean.

with dust concentrations on the basis of van den Heever et al. (2006)), it was found that more than half of ice particles produced were less than $100 \mu \mathrm{m}$, while the observed ice particles in both cases are very large, with sizes generally larger than $200 \mu \mathrm{m}$, based on both the 2DS and CIP images (Fig. 2).
Since new ice crystals form on tiny ice nuclei with at the dust sizes when activating in the deposition mode, so they are put into the first bin of the ice crystal spectrum which is about 4 $5 \mu \mathrm{m}$ in diameter, and thus a small ice crystal mode persists in the simulated clouds. For this reason, and the fact that the Meyers parameterization for deposition nucleation does not well represent the activation properties of mineral dust particles, simulations did not give results in good agreement with observed cloud properties. With our implementation of the immersion freezing (i.e., DeMott et al., 2013) as described above (i.e., the largest drops freeze first and then the smaller ones), we are able to obtain a majority of large ice particles in our simulations, matching better with observations.

\subsection{Design of numerical experiments}

Simulations are performed using realistic initial and lateral boundary conditions. Two nested domains with a horizontal resolution of 10 and $2 \mathrm{~km}$ are used (Fig. 3) with 51 vertical levels. The numbers of horizontal grid points for domain 1 (coarse-grid domain) and domain 2 (fine-grid domain) are $138 \times 134$ and $301 \times 281$, respectively. We use the one-way nesting approach for the two-domain simulations. For FEB16, three-hourly NCEP (National Centers for Environmental Prediction) North American Model (NAM) Data at $32 \mathrm{~km}$ resolution is processed to provide initial conditions for both domain 1 and domain 2, and also to provide lateral boundary conditions for domain 1 . domains 1 and 2 are run at the same time with a one-way nesting approach. For MAR02, the one-way approach is executed a little differently, i.e., domain 2 is run separately with initial and lateral boundary conditions obtained from a simulation 
Table 1. The CCN and INP setup for the simulations of (a) FEB16 and (b) MAR02.

\begin{tabular}{|c|c|c|c|c|}
\hline Runs & $\mathrm{CCN}\left(\mathrm{cm}^{-3}\right)$ & $\begin{array}{l}{ }^{*} \text { Background } \\
\text { INP }\left(\mathrm{L}^{-1}\right)\end{array}$ & $\begin{array}{l}\text { Dust layer }\left(\mathrm{cm}^{-3}\right) \\
\text { (serve as INP) }\end{array}$ & Lateral boundaries \\
\hline \multicolumn{5}{|l|}{ (a) FEB16 } \\
\hline **LoCCN\&Dust & 32 & 1.0 & 2 at $3.5-6.5 \mathrm{~km}$ & $\begin{array}{l}\text { CCN: } 32 \mathrm{~cm}^{-3} \\
\text { INP: } 1.0 \mathrm{~L}^{-1} \text { plus } \\
\text { dust profile }\end{array}$ \\
\hline ***HiCCN\&Dust & $32 \times 5$ & 1.0 & 2 at $3.5-6.5 \mathrm{~km}$ & $\begin{array}{l}\text { CCN: } 32 \mathrm{~cm}^{-3} \\
\text { INP: } 1.0 \mathrm{~L}^{-1} \text { plus } \\
\text { dust profile }\end{array}$ \\
\hline LoCCN\&NoDust & 32 & 1.0 & No & $\begin{array}{l}\mathrm{CCN}: 32 \mathrm{~cm}^{-3} \\
\text { INP: } 1.0 \mathrm{~L}^{-1}\end{array}$ \\
\hline HiCCN\&NoDust & $32 \times 5$ & 1.0 & No & $\begin{array}{l}\mathrm{CCN}: 32 \mathrm{~cm}^{-3} \\
\text { INP: } 1.0 \mathrm{~L}^{-1}\end{array}$ \\
\hline
\end{tabular}

(b) MAR02

\begin{tabular}{|c|c|c|c|c|}
\hline *LoCCN\&Dust & 145 & 1.0 & 4 at $3-6 \mathrm{~km}$ & $\begin{array}{l}\text { CCN: } 145 \mathrm{~cm}^{-3} \\
\text { INP: } 1.0 \mathrm{~L}^{-1} \text { plus dust profile }\end{array}$ \\
\hline${ }^{* *}$ HiCCN\&Dust & $145 \times 5$ & 1.0 & 4 at $3-6 \mathrm{~km}$ & $\begin{array}{l}\mathrm{CCN}: 145 \mathrm{~cm}^{-3} \\
\text { INP: } 1.0 \mathrm{~L}^{-1} \text { plus dust profile }\end{array}$ \\
\hline LoCCN\&NoDust & 145 & 1.0 & No & $\begin{array}{l}\mathrm{CCN}: 145 \mathrm{~cm}^{-3} \\
\text { INP: } 1.0 \mathrm{~L}^{-1}\end{array}$ \\
\hline HiCCN\&NoDust & $145 \times 5$ & 1.0 & No & $\begin{array}{l}\text { CCN: } 145 \mathrm{~cm}^{-3} \\
\text { INP: } 1.0 \mathrm{~L}^{-1}\end{array}$ \\
\hline
\end{tabular}

\footnotetext{
* The background INP is set to be vertically uniform. Dust layer is only set at certain vertical levels, which serves as additional INP on top of the background INP. All of the INP is fed to the ice nucleation parameterizations to determine their nucleation.

** LoCCN\&Dust is the base run which is evaluated by observations.

*** For HiCCN\&Dust, only the CCN over land with terrain height within $200 \mathrm{~m}$ (i.e., at the Central Valley and coastal plains in Fig. 1) are increased by 5 times.
}

with domain 1 alone (the so-called "nest-down" approach). The initial and lateral boundary conditions for domain 1 are obtained from the three-hourly NCEP North American Regional Reanalysis (NARR) data at $32 \mathrm{~km}$ resolution. Different nesting approaches and large-scale data are used for the FEB16 and MAR02 cases to achieve more realistic results compared with observations. For both cases, the lateral boundary conditions are updated every $3 \mathrm{~h}$.

For FEB16, both domains are run with SBM cloud microphysics and the rapid radiative transfer model for global circulation models (RRTMG) (Iacono et al., 2008) short-wave and long-wave radiation schemes are used to account for aerosol-cloud-radiation interactions based on the droplet effective radius $\left(r_{\mathrm{d}}\right)$ calculated by SBM. With this connection, the long-wave positive forcing due to aerosol indirect effects is very significant for deep convective clouds as shown in Fan et al. (2012b). For MAR02, the same SBM and RRTMG schemes are used in the single-domain run (domain 2).

The setups of $\mathrm{CCN}$ and dust concentrations for FEB16 and MAR02 are shown in Table 1. Due to a lack of CCN measurements on these particular days, the initial $\mathrm{CCN}$ size distribution for the base run (i.e., LoCCN\&Dust) is set using the PCASP measurements under cloud-free conditions and the total $\mathrm{CCN}$ number is adjusted based on the
CDP-measured cloud droplet concentrations. As discussed in Sect. 2, clouds in the ascent period of Flt0206 were formed from the maritime clean air which was decoupled from the boundary layer due to weak inversion near the surface and have cloud droplet concentrations of only about $30 \mathrm{~cm}^{-3}$ (Rosenfeld et al., 2014). On MAR02, cloud droplet concentrations are $\sim 120 \mathrm{~cm}^{-3}$ around the cloud bases. Therefore, the total $\mathrm{CCN}$ concentrations used in the base run (LoCCN\&Dust) are $\sim 32 \mathrm{~cm}^{-3}$ for FEB16 and $145 \mathrm{~cm}^{3}$ for MAR02 (Table 1). The smallest and largest CCN bin sizes (in radius) are 0.05 and $2 \mu \mathrm{m}$ for FEB16, respectively, and 0.063 and $2 \mu \mathrm{m}$ for MAR02, respectively. Also based on the UHSAS and PCASP measurements, $\mathrm{CCN}$ are set to be uniform from the ground to $6.5 \mathrm{~km}$ for FEB16 (ignoring the $\mathrm{CCN}$ differences between the decoupled boundary layer and the layer above it, since aerosols from the decoupled boundary layer do not interact with the clouds above the boundary layer). For MAR02, CCN are uniform within 0-1.5 km, then reduced by half from $1.5-4 \mathrm{~km}$. For altitudes above $6.5 \mathrm{~km}$ for FEB06 and $4 \mathrm{~km}$ for MAR02, an exponential decrease of $\mathrm{CCN}$ is employed. Sea-salt composition is assumed for $\mathrm{CCN}$ activation since the air was under relatively pristine marine aerosol conditions (Rosenfeld et al., 2013, 2014). This also makes our setup of total $\mathrm{CCN}$ concentrations based on the 
(a) FEB16

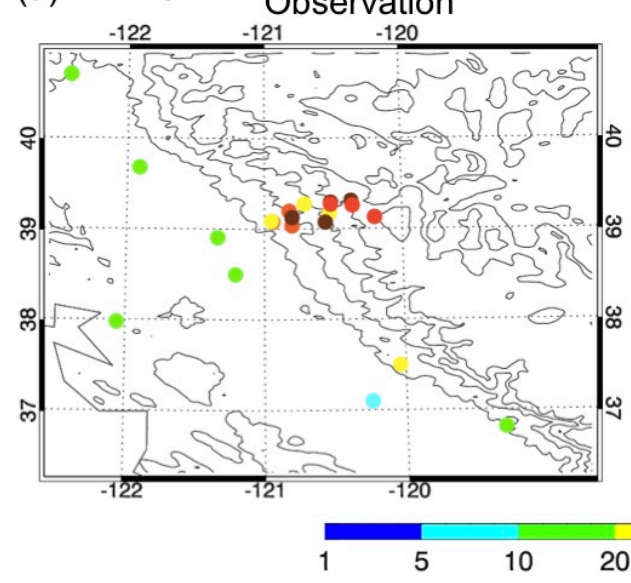

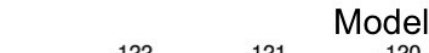

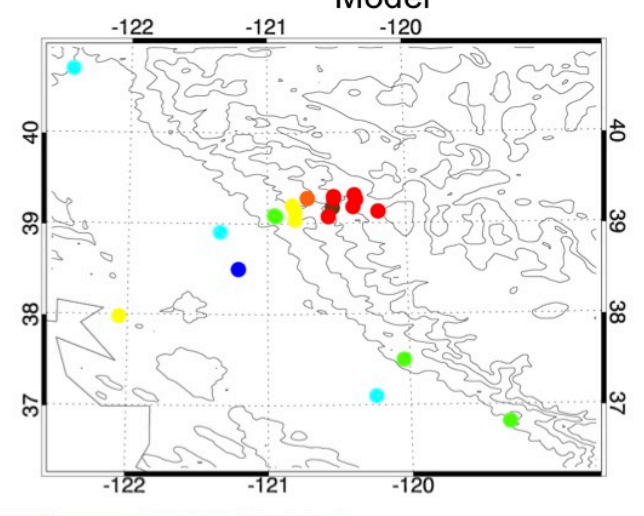

65

$\mathrm{mm}$

(b) MAR02 Observation

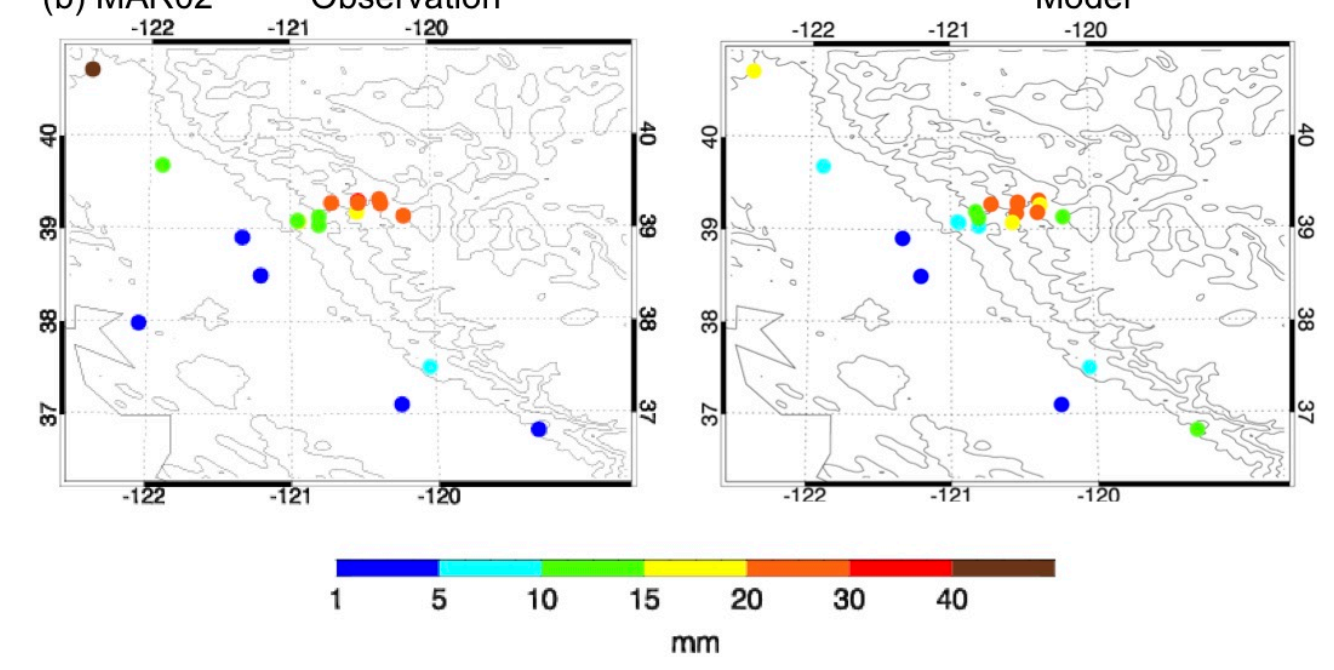

Model $-120$

Fig. 4. Comparison of model accumulated precipitation from the base run (LoCCN\&Dust) with observations for (a) FEB16 and (b) MAR02 during the day (00:00-23:00 UTC). The day refers to 16 February for the FEB16 case, and 2 March for the MAR02 case.

observed droplet concentrations valid since sea salt is easily activated under supersaturation.

Section 2 discussed how we obtained the proxy dust concentration $\left(N_{\text {dust }}\right)$, which is the sum of aerosol particles with diameters larger than $0.5 \mu \mathrm{m}$ under clear-sky conditions. $N_{\text {dust }}$ was $\sim 1-2$ and $\sim 4 \mathrm{~cm}^{-3}$ for FEB16 and MAR02 (Flt0302b only has about 1 min time period showing virtually no ice), respectively. Based on laboratory experiments, the fraction of dust particles acting as effective INP to form ice crystals is generally in the range of $\sim 4-5 \times 10^{-3}$ (Niemand et al., 2012) at temperatures $\sim-22^{\circ} \mathrm{C}$. Based on this information, the ice crystal concentrations should be about $4-10 \mathrm{~L}^{-1}$ for FEB16 and $<20 \mathrm{~L}^{-1}$ for MAR02, which is close to the CFDC-measured effective INP and the ice crystal concentrations measured by 2DS in FEB16 (Creamean et al., 2013). From the vertical distribution of dust, the location of dust is set at 3.5-6.5 km for FEB16 and 3-6 km for MAR02. The dust layer is applied to the entire horizon- tal domain. We understand that dust may also act as CCN. Given that the dust concentration is much lower (1-2 magnitudes) than the $\mathrm{CCN}$ concentrations in these cases, its $\mathrm{CCN}$ effect may be negligible. Therefore, only the effects of dust as INP are examined in this study. To examine the impacts of aerosol particles from local pollution versus long-range transported dust on the winter clouds and precipitation, we conduct three sensitivity runs besides the base run, which are referred to as "HiCCN\&Dust", "LoCCN\&NoDust" and "HiCCN\&NoDust" (Table 1). Local pollution particles in the Central Valley region and along the coastal plains are mainly anthropogenic, which increase CCN concentrations (Moore et al., 2012). We assume no special INP properties for the pollution particles. Therefore, in HiCCN\&Dust, based on the base run (LoCCN\&Dust), we increase CCN concentration by 5 times over land grid points with topographic height less than $200 \mathrm{~m}$, which covers the coastal plains and the Central Valley area as shown in Fig. 3. In LoCCN\&NoDust, the dust 
(a) Flt0216
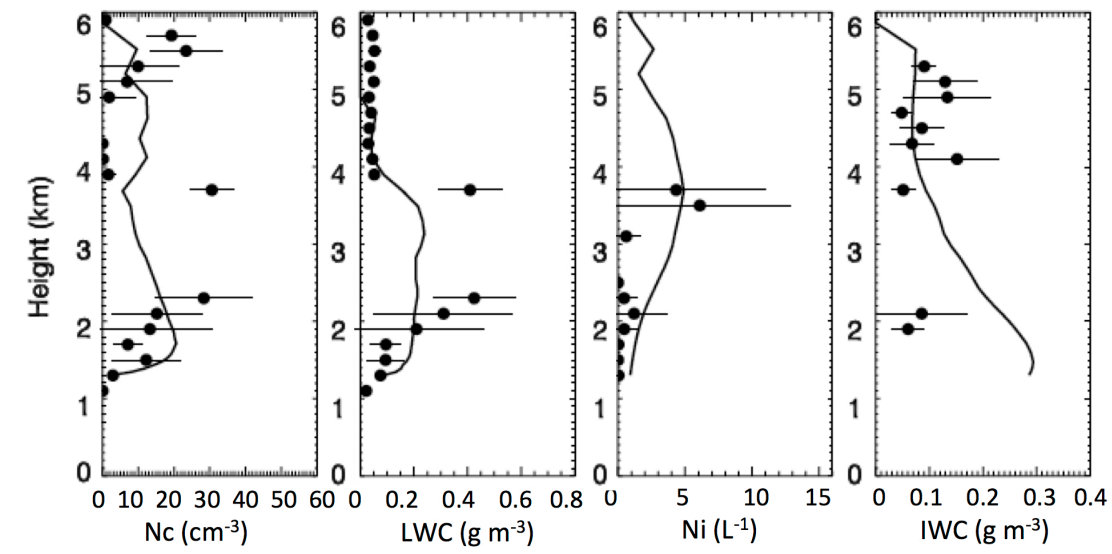

(b) Flt0302a

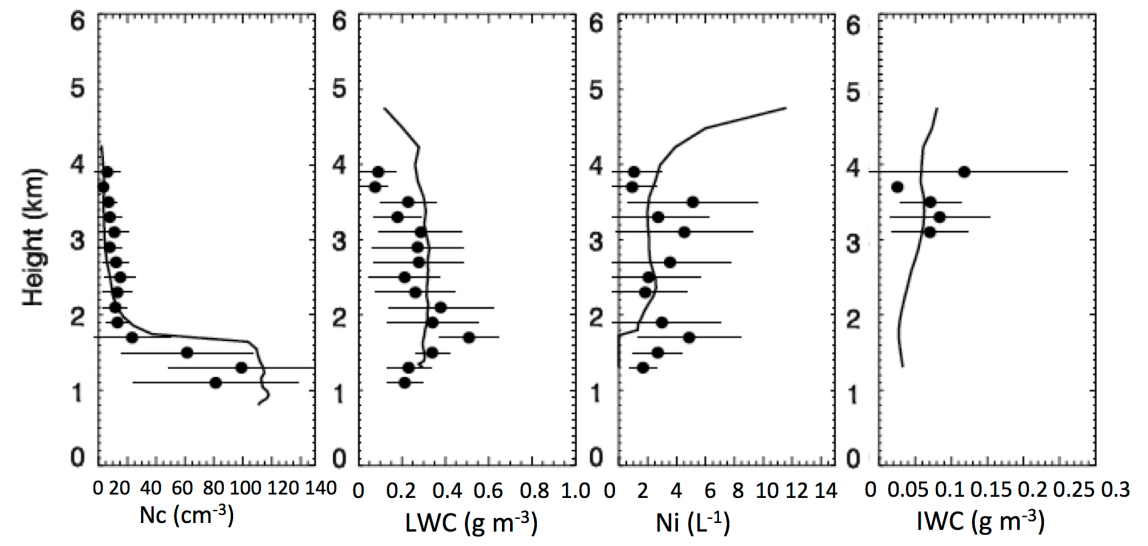

Fig. 5. Comparison of the modeled cloud droplet number concentration $\left(N_{\mathrm{c}}\right)$, liquid-water content (LWC), ice particle number concentration $\left(N_{i}\right)$, and ice-water content (IWC) with aircraft measurements (a) for flt0206 on FEB16 and (b) for flt0302a on MAR02. The black dots denote the observed data. $N_{\mathrm{c}}$ is from CDP, LWC and IWC are from the WCM measurements, and $N_{i}$ is from 2DS. The bars denote standard deviation. The model results are from the base run (LoCCN\&Dust). The model results are averaged over the cloudy points identified by the detection limit of each instrument in the aircraft-measurement domain instead of the flight track due to the extreme heterogeneous nature of the clouds in this region.

layer is removed from the base run to examine the impact of dust as INP. HiCCN\&NoDust is conducted so that we can examine the CCN effects under the condition of no dust, as well as the dust effects in the polluted condition (i.e., high $\mathrm{CCN}$ ). Note that the background INP of $1 \mathrm{~L}^{-1}$ (Table 1) is set to be vertically uniform in the NoDust runs at the initial time step. It is used as input to the ice nucleation parameterization of DeMott et al. (2013) and the contact freezing parameterizations described in Sect. 3.1.2 for calculation of ice nucleation and is treated as being prognostically similar to dust particles.

To avoid artificial dilution of CCN and INP by the inflow air from the lateral boundaries, CCN and INP sources are set at the lateral boundaries that include the outer 5 grid cells on each side of domain. Specifically, the CCN and INP at the lateral boundaries are the same as their initial conditions (Table 1) except for the boundary $\mathrm{CCN}$ in the polluted runs (i.e., HiCCN\&Dust and HiCCN\&NoDust). In those two runs, $\mathrm{CCN}$ at the lateral boundaries are set to be the same as those in the clean runs (Table 1) in order to mimic the clean airflow from the south and, which isolates the impact of pollution produced locally (not transported from other regions). $\mathrm{CCN}$ are diagnosed rather than predicted for cloudy points at the lateral boundaries to prevent excessive droplet nucleation (Fan et al., 2012a).

\section{Results}

\subsection{Comparison with observations}

The base runs (i.e., LoCCN\&Dust) of both FEB16 and MAR02 are evaluated with available observations from aircraft, satellite retrieved data, and surface precipitation data. Most importantly, a radar simulator (Fan et al., 2009) is coupled with WRF-SBM so that we are able to compare the 
(a) FEB16

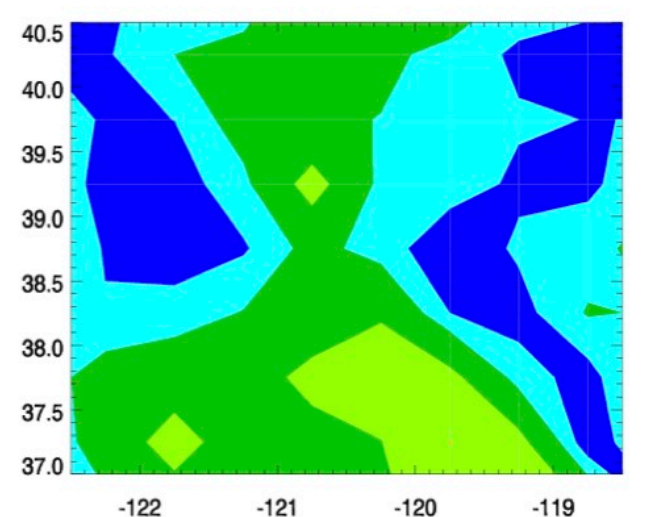

VISST

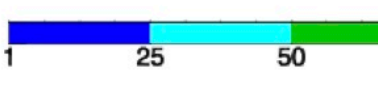

- LWP

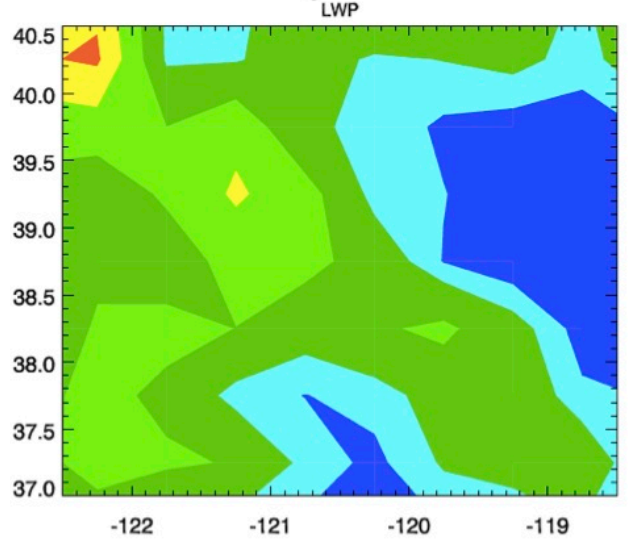

Model

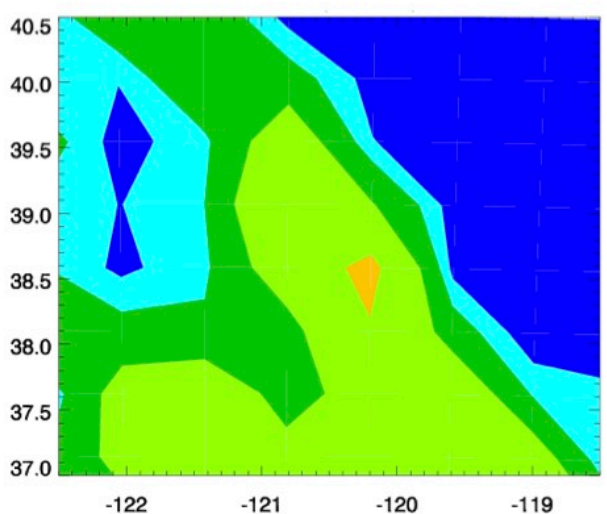

$200-250-2000$

$\mathrm{m}-2$

$\mathrm{m}-2$

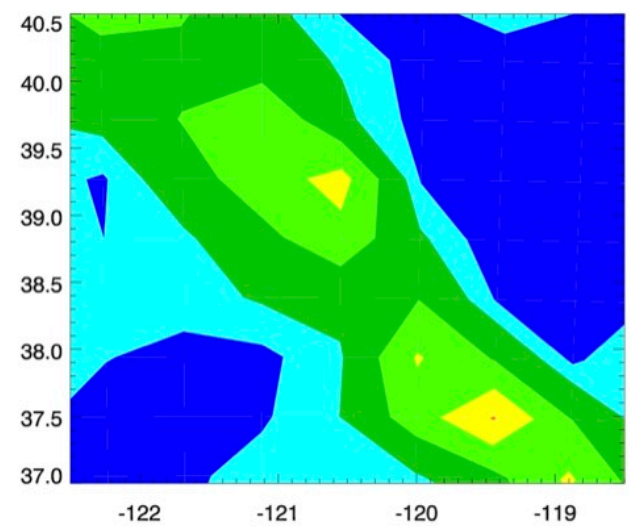

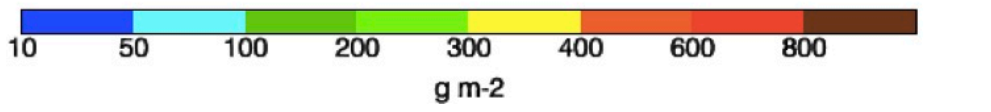

Fig. 6. Comparison of the modeled LWP from the base run (LoCCN\&Dust) with the VISST observations for (a) FEB16 and (b) MAR02. LWP is averaged over the time from 12:00-23:00 UTC of the day when the solar zenith angle $(\theta)$ is less than $80^{\circ}$, since the observational data are only good with $\theta<80$ degree and there are no observations at some hours during 00:00-12:00 UTC. Both model and observations are hourly data. The model values are averaged over the $50 \mathrm{~km}$ scale for comparison with the VISST data grid scale of $0.5^{\circ}$ at the mid-latitudes.

direct radar measurements from the ground-based S-PROF with the model-simulated values, which are calculated based on model-predicted size distribution for each hydrometeor.

First, the accumulated precipitation from 00:00 to 23:00 UTC on 16 February for FEB16 and on 2 March for MAR02 for stations with values larger than $1 \mathrm{~mm}$ are compared with the corresponding results in the base runs (Fig. 4). The model captures the observed spatial pattern of precipitation in both cases, i.e., heavier precipitation for stations on the windward side of the Sierra Nevada and lighter precipitation for stations along the Central Valley. For most stations over the mountains, the modeled precipitation agrees well with observations in both cases. The model underpre- dicts precipitation for most stations along the Central Valley for FEB16, but does a better job for MAR02.

Figure 5 shows a comparison of the modeled cloud microphysical properties with in situ aircraft measurements. The observed droplet concentration $\left(N_{\mathrm{c}}\right)$ is from the CDP measurements with a size range of $2-50 \mu \mathrm{m}$ and the modeled values are integrated over the same size range. On FEB16, the model reasonably reproduces $N_{\mathrm{c}}$ and LWC during the ascent period of the flight, especially for the cloud layer below $3.5 \mathrm{~km}$ (Fig. 5a). The model also captures the supercooled droplet layer above $3.5 \mathrm{~km}$. The values of $N_{i}$ from the simulation are in good agreement with the 2DS measurements below $3.6 \mathrm{~km}$. The 2DS was not operating above $3.6 \mathrm{~km}$ on Flt0216, but obviously ice particles are present since the 
observed IWC is significant and the model captures it very well. IWC is approximately a few times larger than LWC (between $3.8-5.2 \mathrm{~km}$ ), consistent with the observed large cloud ice fraction due to the dust layer (Fig. 2 of Creamean et al., 2013). For MAR02, the simulation captures the vertical variation of $N_{\mathrm{c}}$ very well. The modeled LWC values also agree with observations. Note that the large horizontal bars in the measured $N_{\mathrm{c}}$ below $1.8 \mathrm{~km}$ suggest that the cloud field is highly variable. The modeled IWC is reasonably good, but $N_{i}$ tends to be lower than observed. The model simulates a few deeper clouds in the flight domain, resulting in the higher modeled cloud top seen in Fig. 5b. On the other hand, the aircraft did not fly above $4 \mathrm{~km}$ in Flt0302a, and we do not know if there were clouds above this height or not.

The modeled LWP from the base runs is compared with the VISST LWP as shown in Fig. 6. Note that the model values are averaged over the $50 \mathrm{~km}$ scale, which is close to the grid scale of $\sim 0.5^{\circ}$ for the VISST data at mid-latitudes. For FEB16, the modeled LWP agrees reasonably well with the VISST LWP in both magnitudes and spatial patterns, except for overestimating the LWP over the Sierra Nevada and southern California. For MAR02, the modeled LWP agrees with the VISST LWP over the mountains, but it is significantly lower than the observations over the coastal plains and the Central Valley.

Figure 7 shows a comparison of the histograms of radar reflectivity $\left(Z_{\mathrm{e}}\right)$ and Doppler velocity $(\mathrm{Vd})$ from S-PROF with those simulated by the radar simulator coupled with WRFSBM. Note that the original observed data are at a frequency of $\sim 1$ per minute. The data shown in Fig. 7 are sampled every $10 \mathrm{~min}$ to match with the model data. Since the S-PROF data are time series at a single point (SPD), the model data used in Fig. 7 are averages over four adjacent grid points around SPD. The model reproduces the observed probability distribution of $Z_{\mathrm{e}}$ very well in both cases except for $Z_{\mathrm{e}}$ larger than $20 \mathrm{dBZ}$. The model simulation underestimates the frequency of $\mathrm{Vd}>1 \mathrm{~m} \mathrm{~s}^{-1}$ and $\mathrm{Vd}<-2 \mathrm{~m} \mathrm{~s}^{-1}$ compared to observations on FEB16, but does a much better job on MAR02, though it still underestimates the occurrence of $\mathrm{Vd}<-2 \mathrm{~m} \mathrm{~s}^{-1}$. The underprediction of both large absolute $\mathrm{Vd}$ and high $Z_{\mathrm{e}}$ indicates the simulated convection may be not as strong as the observed convection at the locations around SPD.

\subsection{Aerosol effects}

In this section, we examine how the local pollution particles and long-range transported dust change modeled cloud properties and precipitation and which is a more significant factor impacting local precipitation and climate for the cases simulated. Figure 8 presents the total rain and snow mass concentrations at the lowest model level $(\sim 50 \mathrm{~m}$ above terrain height) in domain 2 from the four runs for FEB16 and MAR02. In the base run LoCCN\&Dust, snow precipitation is significant in both cases because precipitation is mainly located over the Sierra Nevada, but the rain fraction is much

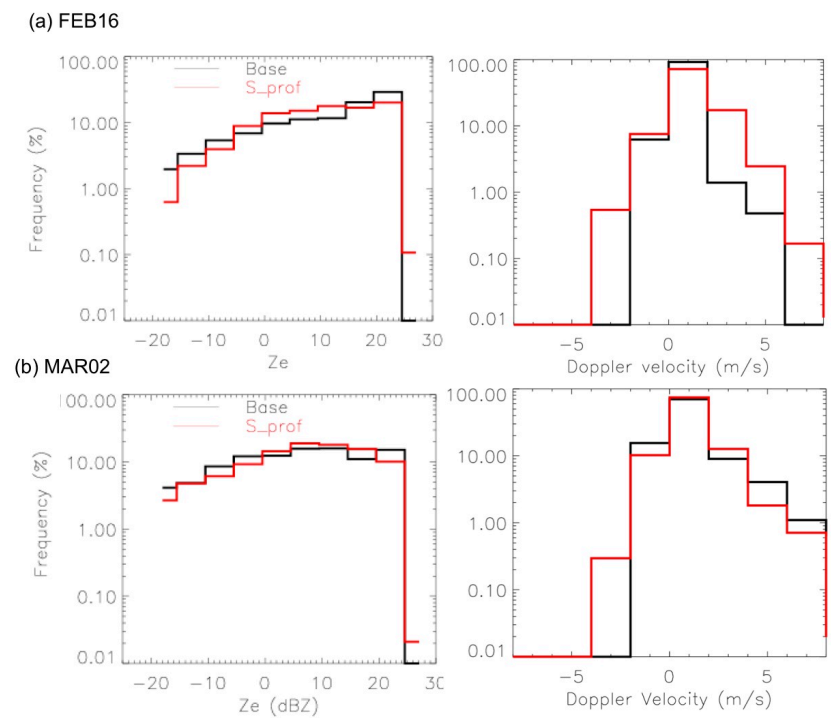

Fig. 7. Comparison of the modeled frequency distribution (black) of radar reflectivity and Doppler velocity from the radar simulator of the base run with the S-PROF measurements (red) for (a) FEB16 and (b) MAR02. The S-PROF (2875 Mhz) is located at Sacramento.

higher on MAR02 (0.18 on FEB16 and 0.5 on MAR02), consistent with radar and satellite estimates given in Creamean et al. (2013). As discussed in Sect. 2, MAR02 is warmer and the clouds are shallower. By removing the aerosol layer which has ice nucleating properties of mineral dust from the base run (LoCCN\&NoDust), snow mass concentration is reduced by $\sim 35 \%$ on FEB16 and $\sim 50 \%$ on MAR02, while raindrop- mass concentration is increased by $\sim 3$ times on FEB16 and only $\sim 30 \%$ on MAR02. When examining the raindrops and snow in clouds (Fig. 9), we find that on FEB16, the raindrop-mass mixing ratio is increased by $\sim 30 \%$ when dust is removed, accompanied by a substantial reduction of snow mass (by $50 \%$ over the mountains). The same trends exist on MAR02 but the changes are smaller (Fig. 10), because the case is warmer and the clouds are shallower.

By comparing HiCCN\&NoDust with HiCCN\&Dust in Fig. 8, we see that dust increases snow precipitation by similar magnitudes (i.e., $34 \%$ on FEB16 and $47 \%$ on MAR02) under the polluted condition compared with the clean condition in both cases. CCN effects decrease rain by $7-15 \%$ and increase snow by $3 \%$ under both dust and no-dust conditions on FEB16. On MAR02, CCN effects are very small because the pollution from the Central Valley does not reach most of the clouds; this will be discussed further.

To more clearly show where significant changes of precipitation occur from the coastal area to the Sierra Nevada, a cross section is used to compare the simulations (dashed gray line in Fig. 11a). Surface precipitation accumulated during the day is integrated over a strip of area parallel to the blue line in Fig. 11a and then divided by the total number of grid points. Fig. 11b (FEB16) and 11c (MAR02) present the 
(a) FEB16

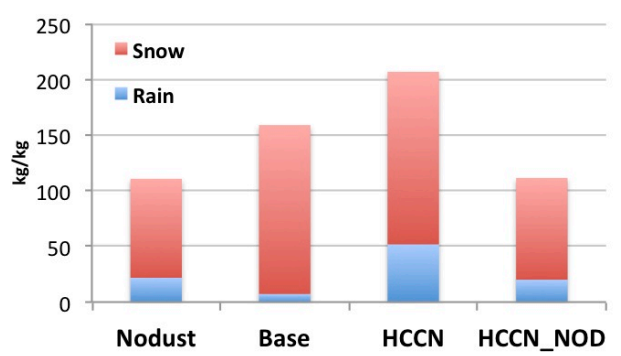

(b) MAR02

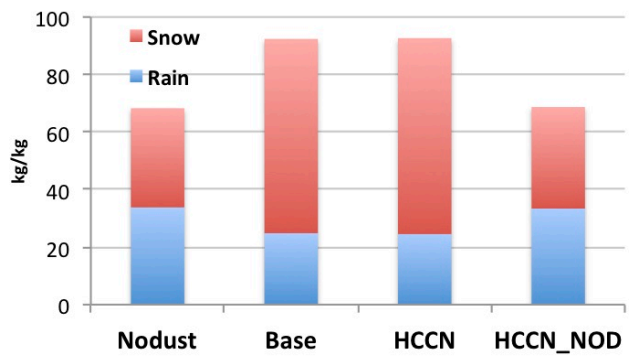

Fig. 8. Total rain (blue) and snow (red) mass concentrations at the lowest model level ( $\sim 50 \mathrm{~m}$ above terrain height) summed over the domain 2 and during the day (00:00-23:00 UTC) from all the simulations shown in x-axis for (a) FEB16 and (b) MAR02.

LoCCN\&NoDust
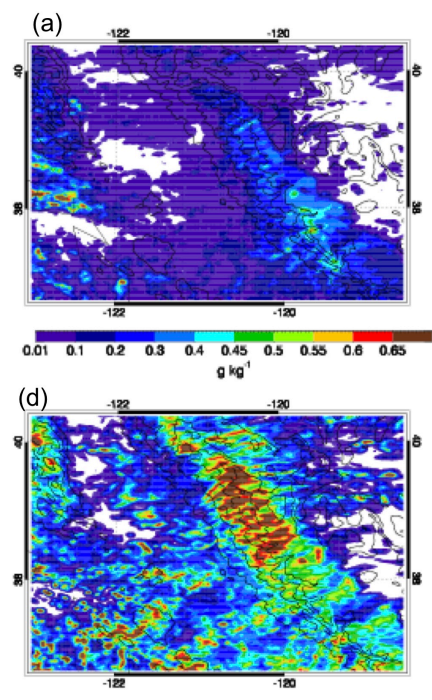

$0.0010 .0060 .010 .020 .03 \underset{g}{0.04} 0.060 .08 \quad 0.07 \quad 0.08$
LoCCN\&Dust
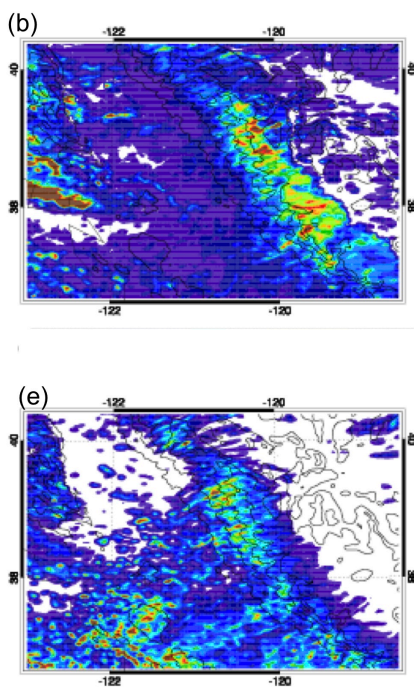

HiCCN\&Dust

(c)
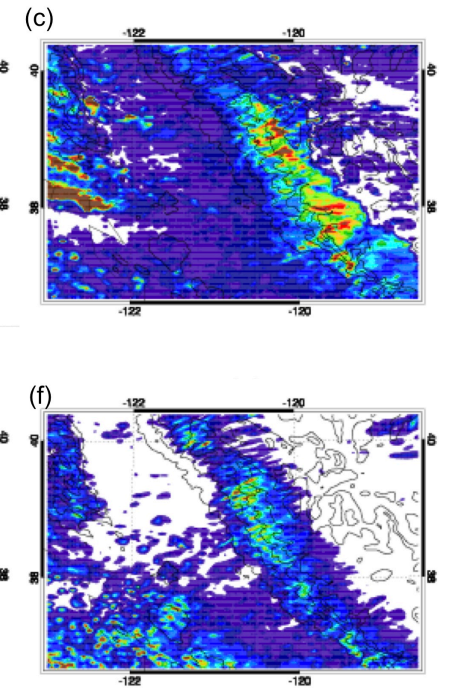

Fig. 9. Mass mixing ratios of in-cloud raindrops and snow from (a) LoCCN\&NoDust, (b) LoCCN\&Dust, and (c) HiCCN\&Dust for FEB16.(a), (b), and (c) are for precipitating ice (i.e., snow + graupel but graupel content is negligible compared with snow) and (d), (e) and (f) are for raindrops. The data are averaged over the cloudy grids (with the sum of cloud water and cloud ice $>10^{-6} \mathrm{~kg} \mathrm{~kg}^{-1}$ ) during 00:00-23:00 UTC and below $7 \mathrm{~km}$.

differences in the mean accumulated precipitation between the runs to compare the $\mathrm{CCN}$ and dust effects (percentage changes are presented in Fig. 11d, e). By removing the dust layer under the clean condition (red solid line), the mean precipitation over the mountains can be reduced by up to $3.2 \mathrm{~mm}$ $(\sim 15 \%)$ on 16 February. Over the Central Valley, the reduction in mean precipitation is less $(\sim 1 \mathrm{~mm})$ but the percentage change is even larger. For MAR02, the reduction in precipitation by removing dust is small from the coast to Central Valley and in the mountains, but is up to $15 \%$ on the windward slopes (west side of the mountains). Along the strips, dust effects on surface precipitation are more significant under the polluted condition (the red dashed line) on FEB16 but are similar to the clean condition on MAR02 (i.e., the red dashed line is very close to the red solid line in Fig. 11c).
Therefore, Figs. 8-11 consistently show that dust increases snow precipitation dramatically over the region in both cases, for both high and low CCN conditions. Without the dust layers, snow can be reduced by $40-50 \%$ and the precipitation over the Central Valley and the windward slopes (west slope) of the mountains can be reduced by $10-20 \%$. As the fraction of aerosols that serve as effective INP increases, freezing of water drops is enhanced, leading to much more snow formation (Table 2). The increase of snow is because of the stronger WBF and riming processes as the total riming growth is increased by three times and the total ice deposition growth is increased by five times in LoCCN\&Dust compared with LoCCN\&NoDust. We also see that ice deposition growth is dominant, which is about 20 times larger than the rimming growth in both dust and no-dust cases, consistent 
LoCCN\&NoDust
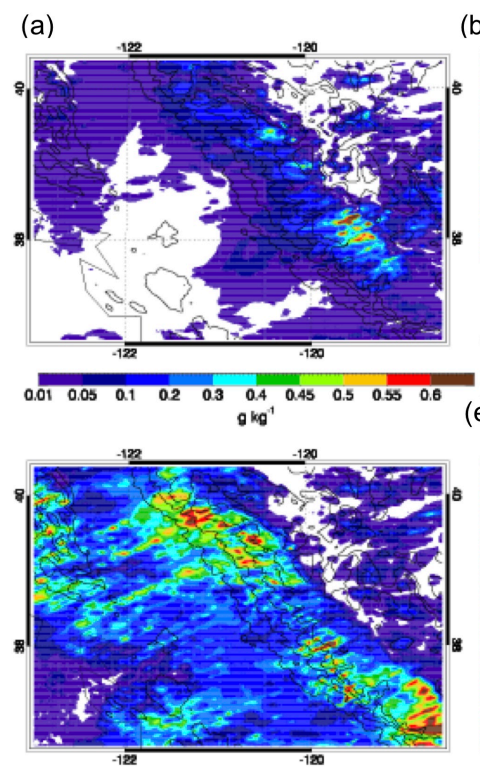

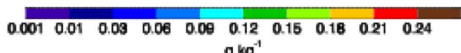

LoCCN\&Dust

(b)

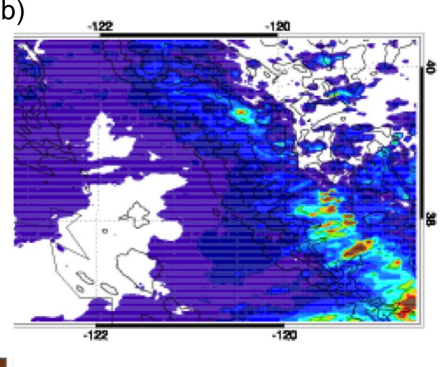

(e)

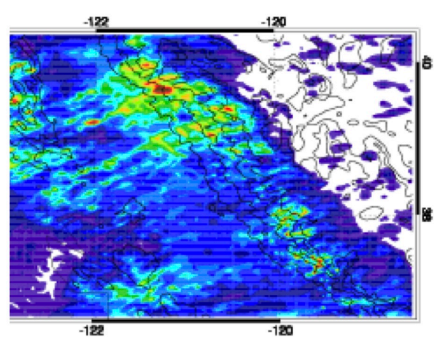

HiCCN\&Dust

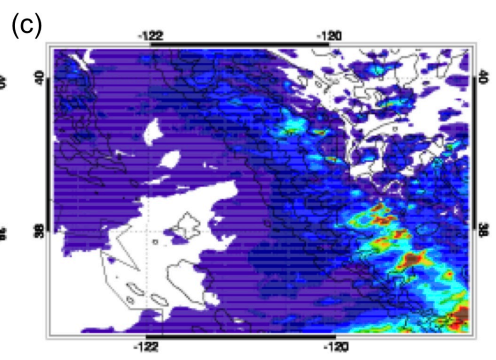

(f)

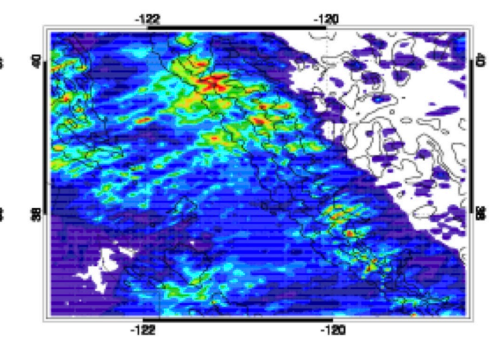

Fig. 10. Same as Fig. 9, except for MAR02.

with the findings of Saleeby et al. (2013). Note that riming efficiency may be reduced due to the smaller ice particles size in the dust run, but the riming occurs more extensively due to increased ice particle number concentrations. Ice crystal number and mass concentrations are very small relative to snow in both dust and no-dust cases. In the model, ice forms through immersion and contact freezing of drops. As the large drops freeze first, it is likely that many of the ice particles formed are immediately placed in the snow category when their size is large than $150 \mu \mathrm{m}$. Without dust, both snow and ice number and mass concentrations are reduced by over $50 \%$, accompanied by an increase of raindrop number and mass concentrations (Table 2). Therefore, by freezing more water drops mainly through immersion freezing (contact freezing contributes little since immersion freezing consumes most of the INP) when INP increases, dust particles increase snow precipitation by $10-20 \%$ over the Central Valley and the Sierra Nevada.

As for the effects of local pollution particles which serve as $\mathrm{CCN}$, increasing $\mathrm{CCN}$ over the Central Valley and coastal plains (HiCCN\&Dust) from the base run (LoCCN\&Dust) increases the accumulated surface precipitation averaged over the grid points along the strips shown in Figure 11a on the windward slopes of the mountains for both cases (blue solid line in Fig. 11d and e). In fact, in-cloud raindrop mass is reduced in HiCCN\&Dust compared to LoCCN\&Dust, especially over the Central Valley and the southern part of the mountains on FEB16 (Fig. 9e, f), since the coalescence of smaller droplets is less efficient in forming rain in the pol- luted condition. Therefore, it is suggested that ice and snow contribute to the increase of surface precipitation. Comparing Fig. 9c with 9b, in-cloud snow increases in HiCCN\&Dust from LoCCN\&Dust, especially over the southern part of the Sierra Nevada. The results in Table 2 also show a similar trend when they are averaged over the domain. For MAR02, increasing $\mathrm{CCN}$ does not reduce raindrop-mass concentration over the Central Valley and snow over the mountains also does not increase (Fig. 10) compared with the base run, resulting in no change in both rain and snow near the surface, as shown in Fig. 8.

Under the conditions of no dust and bio, the effects of local pollution on rain and snow near the surface are smaller: pollution aerosols suppress rain by $8 \%$ and increase snow by $3 \%$ on FEB16. Figure $11 \mathrm{~d}$ shows that the surface precipitation from the Central Valley to the lower part of windward slope of the mountains is reduced by $5-9 \%$ but is increased around the peak and lee side of the mountains on FEB16 (blue dashed line), consistent with Rosenfeld and Givati (2006) and Lynn et al. (2007) in which dust was not present or considered. On MAR02, rain is suppressed by only $1 \%$ and snow is increased by $3 \%$ (Fig. 8; compare HiCCN\&NoDust with LoCCN\&NoDust), and the surface precipitation is also decreased slightly for the Central Valley but increased over the slope.

Figure 9e, f and Fig. 10e, f show that increasing CCN locally (i.e., over the Central Valley and coastal plains) reduces in-cloud raindrop mass and number from autoconversion of droplets especially for the southern part of the Central 
Table 2. Cloud microphysical properties from the simulations of (a) FEB16 and (b) MAR02. Data shown are averaged over all of grid points in domain 2 below $7 \mathrm{~km}$ during the day (00:00-23:00 UTC). The CCN effect is calculated by (HiCCN\&Dust-LoCCN\&Dust)/LoCCN\&Dust $\cdot 100$, and the dust effect is calculated by (LoCCNNoDust-LoCCN\&Dust)/LoCCN\&Dust · 100. The symbols in the table are defined as: Nc and Qc denote droplet number concentration and mass mixing ratio, $\mathrm{Nr}$ and $\mathrm{Qr}$ denote raindrop number concentration and mass mixing ratio, $\mathrm{Ni}$ and Qi denote cloud ice number concentration and mass mixing ratio, Ns and Qs denote snow number concentration and mass mixing ratio, and $\mathrm{Ng}$ and $\mathrm{Qg}$ denote graupel number concentration and mass mixing ratio, respectively.

\begin{tabular}{|c|c|c|c|c|c|}
\hline & LoCCN\& NoDust & LoCCN\& Dust & HiCCN\& Dust & CCN effect $(\%)$ & Dust effect (\%) \\
\hline \multicolumn{6}{|l|}{ (a) FEB16 } \\
\hline $\mathrm{Nc}\left(\mathrm{cm}^{-3}\right)$ & 4.72 & 3.53 & 6.19 & 75.33 & 33.66 \\
\hline $\mathrm{Nr}\left(\mathrm{L}^{-1}\right)$ & 1.67 & 0.73 & 0.58 & -20.41 & 127.43 \\
\hline $\mathrm{Ni}\left(\mathrm{L}^{-1}\right)$ & 0.01 & 0.05 & 0.05 & 1.94 & -72.54 \\
\hline Ns $\left(\mathrm{L}^{-1}\right)$ & 0.17 & 0.49 & 0.50 & 1.73 & -64.93 \\
\hline $\mathrm{Ng}\left(\mathrm{L}^{-1}\right)$ & 0.04 & 0.03 & 0.03 & -14.00 & 17.52 \\
\hline $\mathrm{Qc}\left(\mathrm{mg} \mathrm{kg}^{-1}\right)$ & 31.75 & 21.26 & 22.38 & 5.28 & 49.35 \\
\hline $\mathrm{Qr}\left(\mathrm{mg} \mathrm{kg}^{-1}\right)$ & 11.11 & 3.92 & 3.05 & -22.22 & 183.85 \\
\hline Qi $\left(\mathrm{mg} \mathrm{kg}^{-1}\right)$ & 0.002 & 0.009 & 0.010 & 2.44 & -74.41 \\
\hline $\mathrm{Qs}\left(\mathrm{mg} \mathrm{kg}^{-1}\right)$ & 43.45 & 71.92 & 75.18 & 3.14 & -39.59 \\
\hline $\mathrm{Qg}\left(\mathrm{mg} \mathrm{kg}^{-1}\right)$ & 5.22 & 2.90 & 2.46 & -15.34 & 79.90 \\
\hline \multicolumn{6}{|l|}{ (b) MAR02 } \\
\hline $\mathrm{Nc}\left(\mathrm{cm}^{-3}\right)$ & 9.87 & 9.59 & 16.77 & 74.96 & 2.91 \\
\hline $\mathrm{Nr}\left(\mathrm{L}^{-1}\right)$ & 3.32 & 2.73 & 2.64 & -3.26 & 21.37 \\
\hline $\mathrm{Ni}\left(\mathrm{L}^{-1}\right)$ & 0.01 & 0.06 & 0.06 & 6.43 & -89.91 \\
\hline Ns $\left(\mathrm{L}^{-1}\right)$ & 0.11 & 0.37 & 0.38 & 4.61 & -71.36 \\
\hline $\mathrm{Ng}\left(\mathrm{L}^{-1}\right)$ & 0.00 & 0.01 & 0.01 & 5.03 & -27.11 \\
\hline $\mathrm{Qc}\left(\mathrm{mg} \mathrm{kg}^{-1}\right)$ & 26.63 & 24.59 & 26.11 & 6.16 & 8.27 \\
\hline $\operatorname{Qr}\left(\mathrm{mg} \mathrm{kg}^{-1}\right)$ & 20.00 & 14.08 & 13.94 & -0.97 & 42.08 \\
\hline Qi $\left(\mathrm{mg} \mathrm{kg}^{-1}\right)$ & 0.001 & 0.013 & 0.014 & 4.79 & -89.88 \\
\hline $\mathrm{Qs}\left(\mathrm{mg} \mathrm{kg}^{-1}\right)$ & 21.35 & 43.91 & 45.07 & 1.50 & -51.38 \\
\hline $\operatorname{Qg}\left(\mathrm{mg} \mathrm{kg}^{-1}\right)$ & 0.57 & 0.54 & 0.58 & 7.32 & 7.14 \\
\hline
\end{tabular}

Valley and the mountains. The increase of precipitation by the increased CCN occurs mainly on the upper slopes of the Sierra Nevada (Fig. 11). In contrast to deep convective clouds, cloud top temperatures were warmer $\left(>-36^{\circ} \mathrm{C}\right)$, so increased droplet numbers in the polluted condition did not influence ice formation via homogeneous freezing. We see a significant increase of $N_{\mathrm{c}}$ and reduced $N_{\mathrm{r}}$ for clouds that ascend from the Central Valley to the foothills at the $800 \mathrm{~m}$ altitude. The suppression of warm rain in the Central Valley and foothills by the increased CCN (Fig. 9f) allows more condensates (i.e., more droplet number and mass) to feed the ice generation regime on the upper slopes, leading to more snow formation through more riming and enhances precipitation. Note that both location and concentration of pollution are very important in determining whether riming and snow are reduced or increased. The hypothetical polluted environment simulated is moderate, since $\mathrm{CCN}$ are only increased by 5 times based on a very pristine condition of $\mathrm{CCN} \sim 30 \mathrm{~cm}^{-3}$. Furthermore, $\mathrm{CCN}$ are not increased over the mountain terrain so they are confined to the low-lying areas in the Central Valley and coastal plains. If $\mathrm{CCN}$ are increased over the entire domain, $N_{\mathrm{c}}$ in the orographic clouds could increase sufficiently to reduce riming as the droplet size becomes too small. This highlights the sensitivity of aerosol-cloudprecipitation interactions to $\mathrm{CCN}$ relative to the complex terrain.

Under the conditions without dust and bio, increasing $\mathrm{CCN}$ leads to an opposite effect on precipitation (i.e., decreases precipitation) from the Central Valley to the windward slope of the mountains on FEB16 as discussed above. This is consistent with the fact that when dust and bio are present (high INP), CCN increases precipitation due to increases of snow. Without dust and bio, ice nucleation processes become inefficient. The clouds behave like warm clouds, and increasing $\mathrm{CCN}$ suppresses precipitation as conversion of droplets to raindrops is less efficient. For orographic clouds, the suppression of warm rain processes results in more condensates being transported to the higher altitudes and the lee side of the mountains to form ice and snow, leading to more precipitation at those places as shown in Fig. 11b. Similar results were shown in Rosenfeld 
(a)

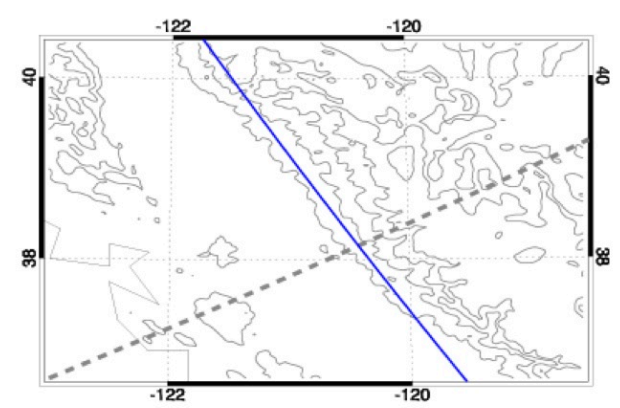

(b)

(c)

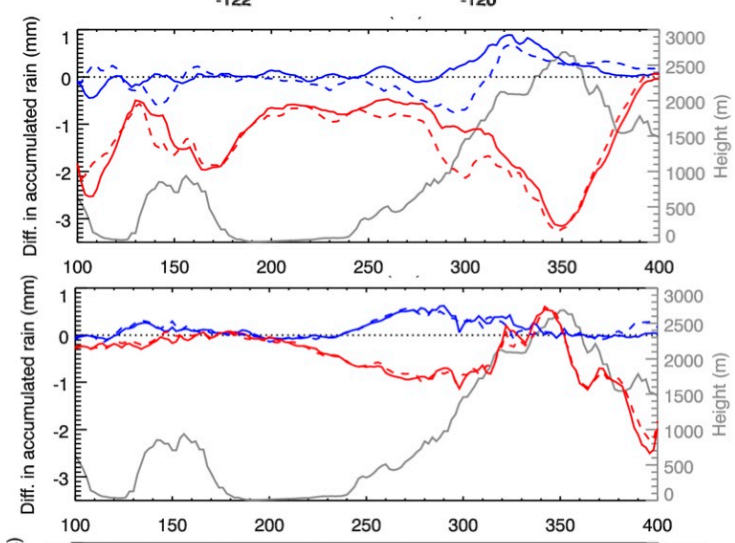

(d)

(e)
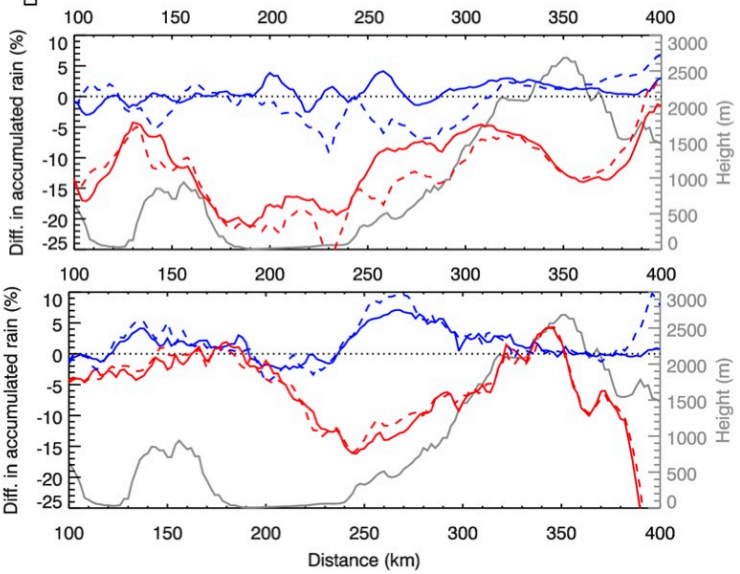

Fig. 11. Differences of the accumulated precipitation averaged over the grid points along a strip one grid cell wide and parallel to the blue line in the (a) along the cross section (i.e., the dashed gray line in (a)) for (b) FEB16 and (c) MAR02. (d) and (e) are the corresponding percentage changes. The blue lines denote the CCN effects under the conditions of dust (solid; HiCCN\&Dust - LoCCN\&Dust) and no dust (dashed; HiCCN\&NoDust - LoCCN\&NoDust), and the red lines denote dust effects by removing the dust layer under the low CCN (solid; LoCCN\&NoDust - LoCCN\&Dust) and high CCN (dashed; HiCCN\&NoDust - HiCCN\&Dust) conditions.

and Givati (2006), Lynn et al. (2007), and Jirak and Cotton (2006), when dust was not present or considered.

Figures 8-11 also clearly show that increasing CCN over the Central Valley and coastal plains have much less impact on precipitation for MAR02 than FEB16. In clouds, both raindrop and snow mass concentrations on MAR02 change little from LoCCN\&Dust to HiCCN\&Dust (Fig. 10). Averaged over domain 2, the reductions of raindrop number and mass from LoCCN\&Dust to HiCCN\&Dust are only $1-3 \%$ for MAR02, much less than the $20 \%$ reduction for FEB16 (Table 2). The same is true when there is no dust. Therefore, clouds on MAR02 are much less sensitive to the increase of CCN than those on FEB16. The reduced sensitivity of snow formed in the clouds for MAR02 is likely related to the warmer temperatures and shallower clouds compared to FEB16.

To understand why increasing $\mathrm{CCN}$ has little effect on raindrop number and mass concentrations for MAR02, we plot the vertical profiles of $\mathrm{CCN}$, droplet and raindrop concentrations only for grid points where high $\mathrm{CCN}$ are applied in HiCCN\&Dust (Fig. 12). It is found that the increase of $N_{\mathrm{c}}$ from LoCCN\&Dust to HiCCN\&Dust on MAR02 is not significant above $1 \mathrm{~km}$, while the increase is very evident by a few times over the entire vertical profile on FEB16. The small change of $N_{\mathrm{c}}$ for MAR02 is due to the negligible change of $\mathrm{CCN}$ above $1 \mathrm{~km}$ (Fig. 12d). So the question is what makes CCN change so little above $1 \mathrm{~km}$ in this case, when the initial CCN in HiCCN\&Dust over the entire vertical profile are increased by 5 times from LoCCN\&Dust for both FEB16 and MAR02. Theoretically, CCN in HiCCN\&Dust should be close to the blue line shown in Fig. 12d. Sensitivity tests performed with uniform CCN vertical distribution from $0-6 \mathrm{~km}$ for MAR02 show similar results, i.e., $\mathrm{CCN}$ decreases dramatically above $1 \mathrm{~km}$. Therefore, the employed vertical distribution of $\mathrm{CCN}$ in the simulations is not a reason.

By examining the wind field at the altitude of $\sim 1.1$ and $3 \mathrm{~km}$ in the Central Valley for FEB16 (Fig. 13) and MAR02 (Fig. 14), we find very strong southwesterly wind blowing through the Central Valley associated with the strong SBJ described in Sect. 2 during 2 March (Fig. 14a). In HiCCN\&Dust where only CCN at the coastal plains and Central Valley are increased, the strong southwesterly wind quickly dilutes the CCN concentrations in the Central Valley area because the air from the western and southern boundaries is much cleaner (i.e., $\mathrm{CCN}$ at the boundaries in HiCCN\&Dust are prescribed the same as in LoCCN\&Dust). Therefore, the CCN in the Central Valley would have little impact on precipitation since they are not entrained by the upslope flow that generates orographic precipitation in the mountains. Note that open boundary conditions are used in the simulation so $\mathrm{CCN}$ can exit the domain from the northern boundary. To further validate the hypothesis, we performed a sensitivity run (red line in Fig. 12e, f) based on HiCCN\&Dust, but with polluted CCN concentration at the southern and western boundaries. Clearly, $\mathrm{CCN}$ concentrations above $1 \mathrm{~km}$ are much larger compared with that in HiCCN\&Dust (close to the blue line except around the cloud base where nucleation scavenging occurs). Therefore, Nc (cloud droplet number concentration) is a few times higher correspondingly, and $\mathrm{Nr}$ is reduced by over $30 \%$. These 
FEB16

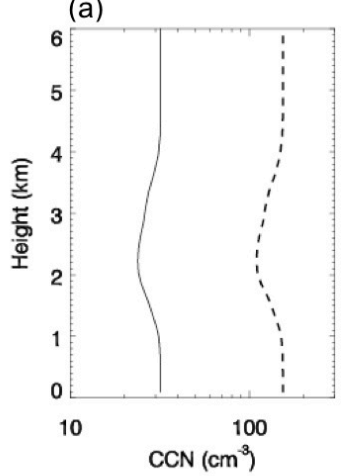

MAR02

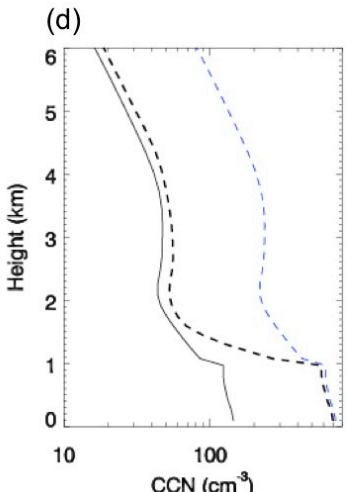

(b)

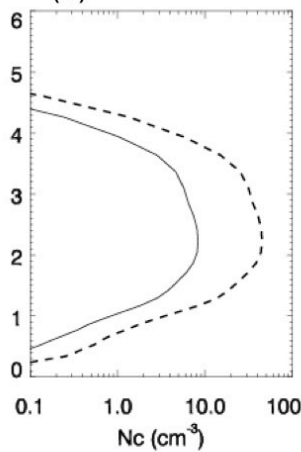

(e)

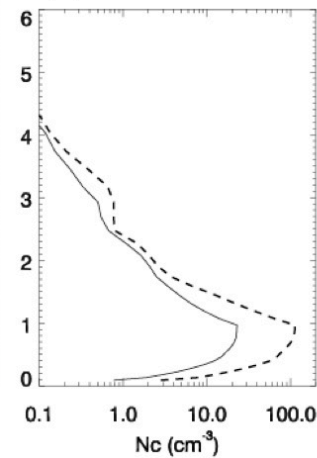

(c)

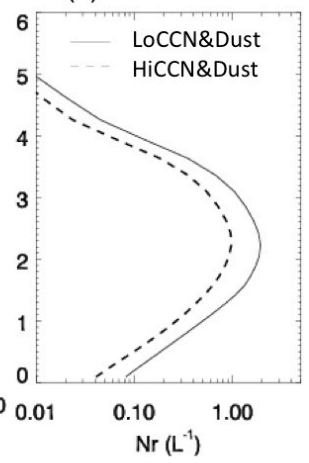

(f)

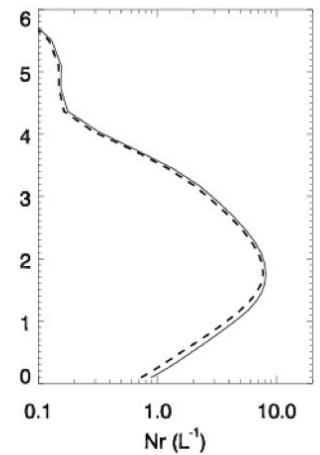

Fig. 12. Vertical profiles of $C C N, N_{c}$, and $N_{r}$ from LoCCN\&Dust (black solid line) and HiCCN\&Dust (black dashed line) for FEB16 (a, $\mathbf{b}, \mathbf{c})$ and MAR02 (d, e, f). The red line denotes a sensitivity run that is based on HiCCN\&Dust but with polluted CCN concentrations at the southern and western boundaries. The data are averaged over the regions where the elevated CCN are applied in HiCCN\&Dust (i.e., land with sea levels < $200 \mathrm{~m}$ ) during 00:00-23:00 UTC. The dashed blue line in (d) for MAR02 denotes the increase of CCN from base-run conditions (black line) by 5 times.

results support the idea that clean boundary air advected to the inner domain dilutes the local pollution over the Central Valley quickly and results in small CCN impact on clouds and precipitation. By contrast, on FEB16, wind at the Central Valley is very weak and the airflow is westerly, which passes through high-CCN regions such as the coastal plains in HiCCN\&Dust (Fig. 13a). To validate the modeled wind fields, we plotted the observed wind from the wind profilers at four stations shown in Figs. 13 and 14 (red color). The simulated wind direction and strength match very well with observations at both lower and higher altitudes on MAR02. The modeled wind fields also agree well with observations at the higher altitudes on FEB16, but do not agree with the observed southerly winds at the lower altitudes before 12:00 UTC. However, the southerly wind from the profilers might be suspicious because the system in this case is dominated by westerly winds as described in Creamean et al. (2013).

Besides horizontal advection, vertical mixing is another important factor that can contribute to the $\mathrm{CCN}$ and droplet concentrations above $1 \mathrm{~km}$. As shown in Fig. 15, consistent with the SBJ that develops in more statically stable conditions, the updraft mass flux is very weak on MAR02 compared to FEB16, where it is more than 2 times larger. There- fore, the transport of $\mathrm{CCN}$ and droplets from the lower altitudes is negligible on MAR02. The observed vertical profile of $N_{\mathrm{c}}$ shown in Fig. 5b is consistent with the small updraft flux. Therefore, the strong dilution by the southerly clean air due to horizontal advection combined with the small vertical transport from altitudes below $1 \mathrm{~km}$ lead to the small change of $\mathrm{CCN}$ above $1 \mathrm{~km}$ from LoCCN\&Dust to HiCCN\&Dust on MAR02. Below $1 \mathrm{~km}$, wind is much weaker and the direction is more southwesterly; therefore, $\mathrm{CCN}$ are much less diluted by the clean air from the lateral boundaries compared to the CCN at higher altitudes. On FEB16, CCN over the entire vertical profile are not diluted because the inflow air is westerly which pass through high $\mathrm{CCN}$ regions in the coastal plains. So, the increased values of $\mathrm{CCN}$ by five times from LoCCN\&Dust to HiCCN\&Dust (Fig. 12a) result in significantly higher cloud droplet concentrations, and raindrop number and mass concentrations are also significantly reduced by more than $20 \%$ (Fig. 12c and Table 2). 

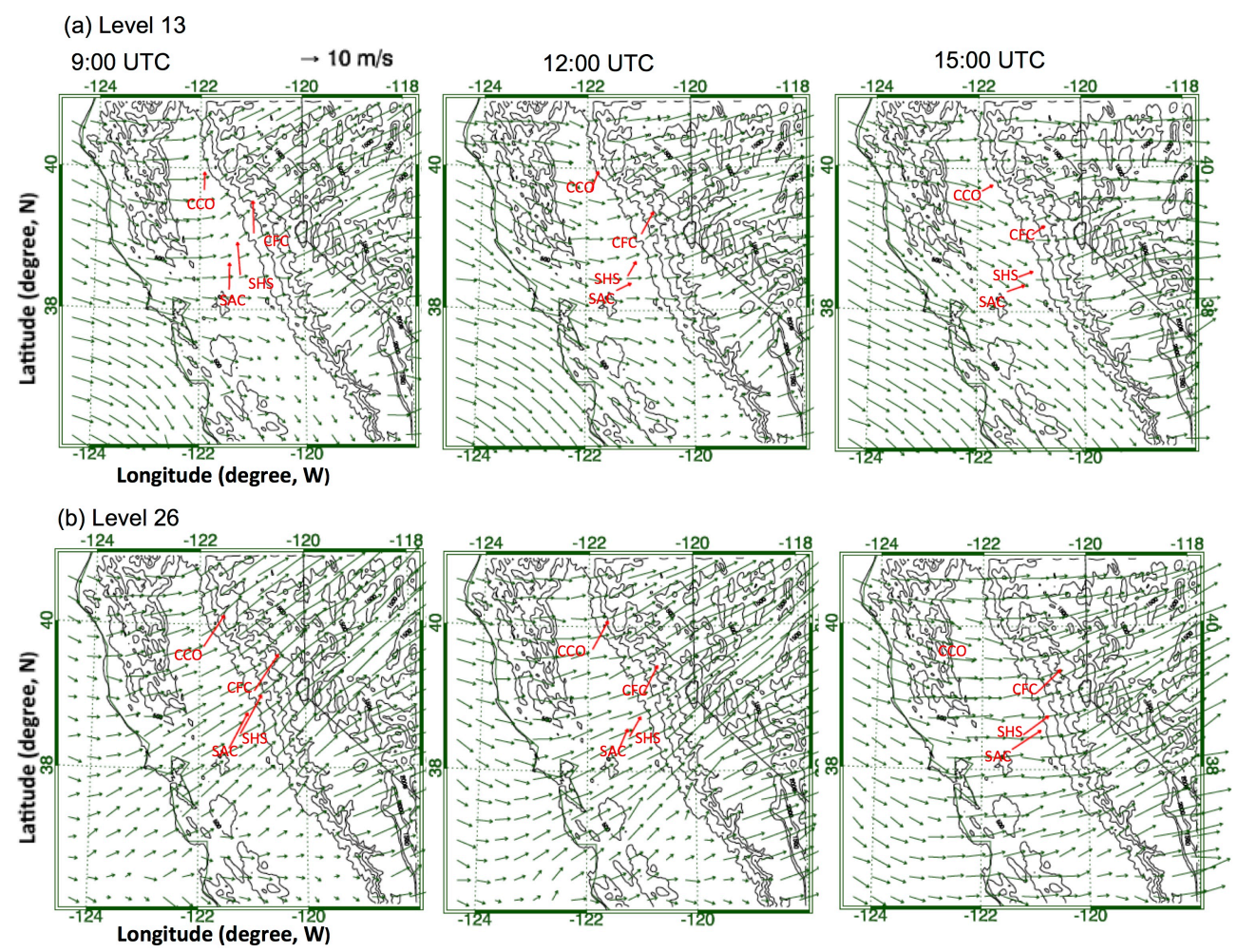

Fig. 13. Wind vectors at the model levels of (a) $13(\sim 1 \mathrm{~km}$ above terrain height) and (b) 26 ( $3 \mathrm{~km}$ above terrain height) for FEB16 at 09:00, 12:00 and 15:00 UTC from the base run (LoCCN\&Dust). The arrow above the first panel is the reference wind speed. The terrain height is denoted by the green contour lines with an interval of $500 \mathrm{~m}$ from 0 to $2000 \mathrm{~m}$. The red arrows denote the measurements from four wind profilers that are located at the stations of CCO (Chico, California), CFC (Colfax, California), SHS (Sloughhouse, California), and SAC (Sacramento, California).

\section{Conclusions and discussion}

Two winter mixed-phase cloud cases occurring on 16 February (FEB16) and 2 March (MAR02) from the CalWater 2011 field campaign have been simulated using the WRF model with a spectral-bin microphysical scheme in which ice nucleation parameterizations are updated to connect with INP so that the effects of aerosols as INP can be explored. The base runs of the two cases are evaluated with a wide range of observations including in situ aircraft measurements of cloud microphysical properties, surface precipitation data, satellite retrieved data, S-PROF radar measurements, and wind profiler data. The model simulations agree reasonably well with the observational data, especially for cloud droplet number concentrations, LWC and accumulated precipitation, despite the complexity of the dynamics and terrain of the region.

By mimicking local pollution from the coastal plains and Central Valley area where particles are effective CCN and including dust and biological aerosol layers that provide effective INP at cold cloud levels, we have examined the effects of local pollution and long-range transported mineral dust on cloud microphysical properties and precipitation. In this study, we do not distinguish the actual composition of the aerosols that are effective INP in forming ice, but evi- dence from the cloud and precipitation residues suggest the presence of mineral dust and biological particles on FEB16 transported aloft from Asia or the Sahara (Creamean et al., 2013) and dust and biological aerosols on MAR02, which we assumed to have similar ice nucleating properties as mineral dust. Model sensitivity experiments indicate that the enhanced INP number concentrations provided by the dust and biological aerosols increased precipitation over the Central Valley and Sierra Nevada Mountain area by $10-20 \%$ on FEB16 and MAR02, by means of increasing $(\sim 40 \%)$ snow formation. These dust effects are more significant in conjunction with the local pollution condition (i.e., high $\mathrm{CCN}$ ) on FEB16. Note that the sensitivity run without the dust layer represents a condition of very low INP. Therefore, the dust effects shown in this study can be treated as the upper bound.

Increasing the local pollution particles increases precipitation by $\sim 5 \%$ with the presence of a dust layer serving as INP, mainly an increased snow-mass mixing ratio on the windward slopes of the Sierra Nevada. The reason for the increased snow under the polluted condition is that the suppression of warm rain in the Central Valley and foothills by the increased $\mathrm{CCN}$ allows more droplets to feed the icegeneration regime of the orographic clouds, increasing snow 

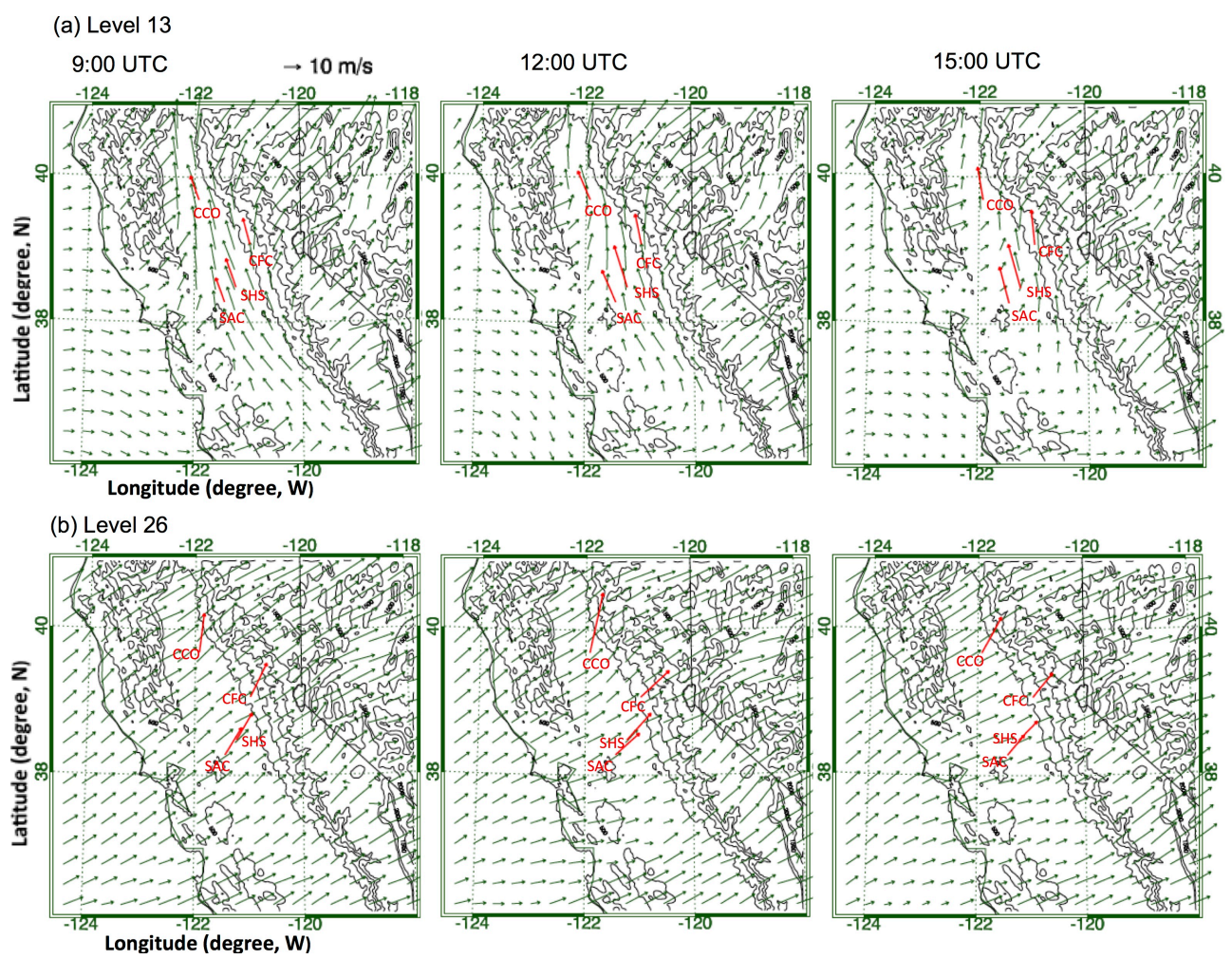

Fig. 14. Same as Fig. 12, only for MAR02.

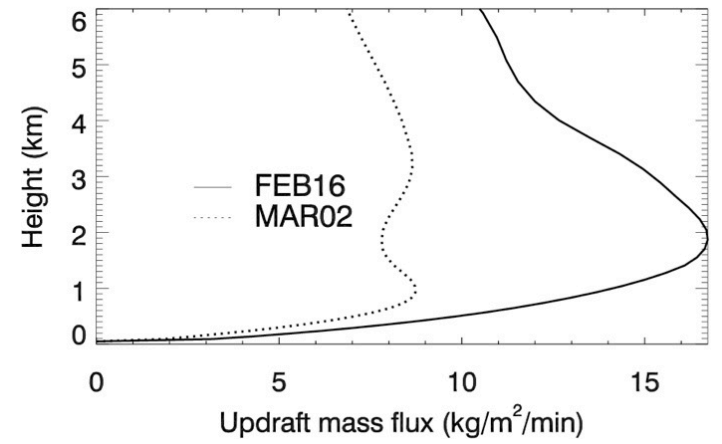

Fig. 15. Updraft mass fluxes averaged over the domain with terrain height within 200 $\mathrm{m}$ and over 00:00-23:00 UTC from the base run (LoCCN\&Dust) for FEB16 and MAR02. The mass fluxes are calculated as (air density · vertical velocity).

through more riming. As discussed earlier, this result could be sensitive to the location and concentration of the local pollution prescribed in the model experiments. However, when dust (INP) is lacking, increasing local pollution (CCN) reduces precipitation by 5-9\% from the Central Valley to the windward slope of mountains as ice microphysical processes become inefficient. Therefore, for the winter clouds under the meteorological conditions described, precipitation is much more susceptible to mineral dust particles acting as INP after transport from Asia and the Sahara (Creamean et al., 2013), and less sensitive to aerosols from local pollution that act as $\mathrm{CCN}$.

Since the winter mixed-phase clouds simulated herein do not reach homogeneous freezing temperatures, there is no mechanism to freeze the large amount of droplets in the polluted condition. Hence $\mathrm{CCN}$ effects on ice microphysical processes are much less significant than in deep convective clouds (Fan et al., 2007), especially for MAR02 when clouds are warmer and shallower. The INP influence mixed-phase clouds mainly through the WBF process, as ice deposition growth is about 20 times larger than riming growth.

The effects of local pollution on warm rain strongly depend on the meteorology and cloud dynamics. As is often observed during the passage of an atmospheric river, an SBJ develops on the foothills of the Sierra Nevada during both FEB16 and MAR02. On FEB16, the atmosphere was less statically stable so the SBJ was not too strong and vertical transport was moderate. In addition, the low-level airflow had a westerly component that passed over the polluted coastal plains. Under such conditions, increasing CCN enhances droplet number concentration over the entire cloud profile and suppresses raindrop formation significantly. On MAR02, however, there was a stronger SBJ and weak vertical transport associated with more stable atmospheric conditions. Dominated by the SBJ at the lower levels, the airflow was more southerly. This vented the valley air to the north and diluted the $\mathrm{CCN}$ entering clouds crossing over the 
mountain barrier. Together with the weak vertical transport, increased $\mathrm{CCN}$ only increased droplet number concentration in the low-level clouds $(<1 \mathrm{~km})$ and had little impact on the droplets and raindrops above them. Since relatively thin layers of low-level clouds do not produce much rain, increasing $\mathrm{CCN}$ has little effect on rain under such conditions. Because of the little impact of $\mathrm{CCN}$ on droplets and raindrops due to the particular meteorological conditions and cloud dynamics in this case, $\mathrm{CCN}$ impacts are similar under both dust and no-dust conditions, and dust effects are also similar whether the condition is clean (low $\mathrm{CCN}$ ) or polluted (high $\mathrm{CCN}$ ).

This study provides a better understanding of not only the properties of orographic clouds and precipitation in a region with complex terrain, but also the potential impacts of anthropogenic aerosols and transported dust on precipitation and local climate. In the Sierra Nevada region of California, water supply depends heavily on precipitation over the mountains that accumulates as snowpack on the ground. The snowmelt-driven streamflow is important for providing water for irrigation in the Central Valley in the summer. By moderating the intensity, phase, and spatial distribution of precipitation, local pollution and transported dust can have important implications for managing long-term water supplies. More studies combining observations and modeling over long time periods are needed to provide further insights on the effects of aerosols on clouds and precipitation under different meteorological conditions.

\section{Supplementary material related to this article is available online at http://www.atmos-chem-phys.net/14/ 81/2014/acp-14-81-2014-supplement.pdf.}

Acknowledgements. This study was supported by the California Energy Commission (CEC) and the Office of Science of the US Department of Energy as part of the Regional and Global Climate Modeling program. Pacific Northwest National Laboratory (PNNL) is operated for Department of Energy (DOE) by Battelle Memorial Institute under Contract DE-AC06-76RLO1830. The G-1 is base funded by the DOE Atmospheric Radiation Measurement Program and the deployment of the G-1 during Calwater was supported by CEC. P. J. DeMott acknowledges partial support from National Science Foundation (NSF) via grant ATM-0841602 and the Department of Energy, Office of Science, Biological and Environmental Research Division contract SC00002354. P. Minnis and J. K. Ayers were supported by the National Aeronautics and Space Administration (NASA) Modeling, Analysis, and Prediction (MAP) Program Program and DOE Interagency Agreement SC0000991. Chun Zhao at PNNL is thanked for the help with the use of the NARR and NAM data. We also thank Jessie Creamean at University of California, San Diego for help in obtaining some of the observational data.

Edited by: C. Hoose

\section{References}

Archuleta, C. M., DeMott, P. J., and Kreidenweis, S. M.: Ice nucleation by surrogates for atmospheric mineral dust and mineral dust/sulfate particles at cirrus temperatures, Atmos. Chem. Phys., 5, 2617-2634, doi:10.5194/acp-5-2617-2005, 2005.

Ault, A. P., Williams, C. R., White, A. B., Neiman, P. J., Creamean, J. M., Gaston, C. J., Ralph, F. M., and Prather, K. A.: Detection of Asian dust in California orographic precipitation: J. Geophys. Res., 116, D16205, doi:10.1029/2010JD015351, 2011.

Bigg, E. K.: The formation of atmospheric ice crystals by the freezing of droplets, Q. J. Roy. Meteor. Soc., 79, 510-519, doi:10.1002/qj.49707934207, 1953.

Borys, R., Lowenthal, D., Cohn, S., and Brown, W.: Mountaintop and radar measurements of anthropogenic aerosol effects on snow growth and snowfall rate, Geophys. Res. Lett., 30, 1538, doi:10.1029/2002GL016855, 2003.

Choularton, T. W. and Perry, S. J.: A model of the orographic enhancement of snowfall by the seeder feeder mechanism, Q. J. Roy. Meteor. Soc., 112, 335-345, 1986

Connolly, P. J., Möhler, O., Field, P. R., Saathoff, H., Burgess, R., Choularton, T., and Gallagher, M.: Studies of heterogeneous freezing by three different desert dust samples, Atmos. Chem. Phys., 9, 2805-2824, doi:10.5194/acp-9-2805-2009, 2009.

Cotton, W., Tripoli, G., Rauber, R., and Mulvihill, E.: Numerical simulation of the effects of varying ice crystal nucleation rates and aggregation processes on orographic snowfall, J. Climate Appl. Meteor., 25, 1658-1680, 1986.

Creamean, J. M., Suski K. J., Rosenfeld, D., Cazorla, A., DeMott, P. J., Sullivan, R. C., White, A. B., Ralph F. M., Minnis P., Comstock J. M., Tomlinson, J, M., and Prather, K. A.: Dust and Biological Aerosols from the Sahara and Asia Influence Precipitation in the Western U.S., Science, 339, 1572-1578, doi:10.1126/science.1227279, 2013.

DeMott, P. J., Prenni, A. J., X. Liu, Kreidenweis, S. M., Petters, M. D., Twohy, C. H., Richardson, M. S., Eidhammer, T., and Rogers, D. C.: Predicting global atmospheric ice nuclei distributions and their impacts on climate. Proc. Natl. Acad. Sci. (USA), 107, 11217-11222, doi:10.1073/pnas.0910818107, 2010.

DeMott, P. J., Möhler, O., Stetzer, O., Vali, G., Levin, Z., Petters, et al: Resurgence in ice nuclei measurement research, B. Am. Meteorol. Soc., 92, 1623-1635, doi:10.1175/2011BAMS3119.1, 2011.

DeMott, P. J., Prenni, A. J., McMeeking, G. R., Sullivan, R. C., Petters, M. D., Tobo, Y., Niemand, M., Möhler, O., Snider, J. R., Sever, G., and Kreidenweis, S. M.: A parameterization of freezing nucleation by mineral dust particles, in preparation for Atmos. Chem. Phys. Discuss., 2013.

Dore, A. J., Choularton, T. W., Fowler, D., and Crossley, A.: Orographic enhancement of snowfall, Environ. Poll., 75, 175-179, 1992.

Fan, J., Zhang, R., Li, G., and Tao, W.-K.: Effects of aerosols and relative humidity on cumulus clouds, J. Geophys. Res., 112, D14204, doi:10.1029/2006JD008136, 2007.

Fan, J., Ovtchinnikov, Comstock, J. M., McFarlane, S., and Khain A.: Ice formation in Arctic mixed-phase clouds: Insights from a 3-D cloud-resolving model with size-resolved aerosol and cloud microphysics, J. Geophys. Res., 114, D04205, doi:10.1029/2008JD010782, 2009. 
Fan, J., Comstock J. M., and Ovchinnikov M.: The cloud condensation nuclei and ice nuclei effects on tropical anvil characteristics and water vapor of the tropical tropopause layer, Environ. Res. Lett., 5, 044005, doi:10.1088/1748-9326/5/4/044005, 2010.

Fan, J., Ghan, S., Ovchinnikov, M., Liu, X., Rasch, P., and Korolev, A.: Representation of Arctic Mixed-Phase clouds and the Wegener-Bergeron-Findeisen Process in Climate Models - Perspectives from a Cloud-Resolving Study, J. Geophys. Res., 116, D00T07, doi:10.1029/2010JD015375, 2011.

Fan, J., Leung, L. R., Li, Z., Morrison, H., Chen, H., Zhou, Y., Qian, Y., and Wang, Y.: Aerosol impacts on clouds and precipitation in eastern China: Results from bin and bulk microphysics, J. Geophys. Res., 117, D00K36, doi:10.1029/2011JD016537, 2012a.

Fan, J., Rosenfeld, D., Ding, Y., Leung, L. R., and Li, Z.: Potential aerosol indirect effects on atmospheric circulation and radiative forcing through deep convection, Geophys. Res. Lett., 39, L09806, doi:10.1029/2012GL051851, 2012b.

Field, P. R., Heymsfield, A. J., Shipway, B. J., DeMott, P. J., Pratt, K. A., Rogers, D. C., Stith, J. L., and Prather, K. A.: Ice in Clouds Experiment - Layer Clouds. Part II: Testing Characteristics of Heterogeneous Ice Formation in Lee Wave Clouds, J. Atmos. Sci., 69, 1066-1079, 2012.

Fletcher, N. H.: The Physics of Rainclouds, 390 pp., Cambridge Univ. Press, Cambridge, UK, 1962.

Hoose, C. and Möhler, O.: Heterogeneous ice nucleation on atmospheric aerosols: a review of results from laboratory experiments, Atmos. Chem. Phys., 12, 9817-9854, doi:10.5194/acp-12-98172012, 2012.

Iacono, M. J., Delamere, J. S., Mlawer, E. J., Shephard, M. W., Clough, S. A., and Collins, W. D.: Radiative forcing by long-lived greenhouse gases: Calculations with the AER radiative transfer models, J. Geophys. Res., 113, D13103, doi:10.1029/2008jd009944, 2008.

Jirak, I. L. and Cotton, W. R.: Effect of air pollution on precipitation along the Front Range of the Rocky Mountains, J. Appl. Meteor. Climatol., 45, 236-245, 2006.

Karydis, V. A., Kumar, P., Barahona, D., Sokolik, I. N., and Nenes, A.: On the effect of dust particles on global cloud condensation nuclei and cloud droplet number, J. Geophys. Res., 116, D23204, doi:10.1029/2011JD016283, 2011.

Khain, A., Leung. L. R., Lynn, B., and Ghan, S.: Effects of aerosols on the dynamics and microphysics of squall lines simulated by spectral bin and bulk parameterization schemes, J. Geophys. Res., 114, D22203, doi:10.1029/2009JD011902, 2009.

Khain, A., Lynn, B., and Dudhia, J.: Aerosol Effects on Intensity of Landfalling Hurricanes as Seen from Simulations with the WRF Model with Spectral Bin Microphysics, J. Atmos. Sci., 67, 365384, 2010

Khain, A. P., Pokrovsky, A., Pinsky, M., Seifert, A., and Phillips, V.: Simulation of effects of atmospheric aerosols on deep turbulent convective clouds using a spectral microphysics mixed-phase cumulus cloud model. Part I: Model description and possible applications, J. Atmos. Sci., 61, 2963-2982, 2004.

Korolev, A. V., Emery, E. F., Strapp, J. W., Cober, S. G., Isaac, G. A., Wasey, M., Marcotte, D.: Small Ice Particles in Tropospheric Clouds: Fact or Artifact? Airborne Icing Instrumentation Evaluation Experiment, B. Am. Meteor. Soc., 92, 967-973, 2011.

Liu, X. and Penner, J.: Ice nucleation parameterization for global models, Meteorol. Z., 14, 499-514, 2005.
Lowenthal, D. H., Borys, R. D., Cotton, W., Saleeby, S., Cohn, S. A., and Brown, W. O. J.: The altitude of snow growth by riming and vapor deposition in mixed-phase orographic clouds, Atmos. Environ., 45, 519-522, doi:10.1016/j.atmosenv.2010.09.061, 2011.

Lüönd, F., Stetzer, O., Welti, A., and Lohmann, U.: Experimental study on the ice nucleation ability of size-selected kaolinite particles in the immersion mode, J. Geophys. Res., 115, D14201, doi:10.1029/2009JD012959, 2010.

Lynn, B. and Khain, A.: Utilization of spectral bin microphysics and bulk parameterization schemes to simulate the cloud structure and precipitation in a mesoscale rain event, J. Geophys. Res., 112, D22205, doi:10.1029/2007JD008475, 2007.

Lynn, B., Khain, A., Rosenfeld, D., and Woodley, W. L.: Effects of aerosols on precipitation from orographic clouds, J. Geophys. Res., 112, D10225, doi:10.1029/2006JD007537, 2007.

Marcolli, C., Gedamke, S., Peter, T., and Zobrist, B.: Efficiency of immersion mode ice nucleation on surrogates of mineral dust, Atmos. Chem. Phys., 7, 5081-5091, doi:10.5194/acp-7-50812007, 2007.

Meyers, M. P., DeMott P. J., and Cotton, W. R.: New primary icenucleation parameterizations in an explicit cloud model, J. Appl. Meteor., 31, 708-721, 1992.

Minnis, P., Nguyen, L., Smith, W. L., Palikonda, R., Ayers, J. K., Doelling, D. R., Nordeen, M. L., Spangenberg, D. A., Phan, D. N., and Khaiyer, M. M.: Large-scale cloud properties and radiative fluxes over Darwin during TWP-ICE, paper presented at the 16th ARM Science Team Meeting, Albuquerque, NM, 27-31 March, 2006.

Moore, R. H., K. Cerully, R. Bahreini, C. A. Brock, A. M. Middlebrook, and A. Nenes: Hygroscopicity and composition of California CCN during summer 2010, J. Geophys. Res., 117, D00V12, doi:10.1029/2011JD017352, 2012.

Muhlbauer, A. and Lohmann, U.: Sensitivity studies of aerosol cloud interactions in mixed-phase orographic precipitation, J. Atmos. Sci., 66, 2517-2538, doi:10.1175/2009JAS3001.1., 2009.

Murray B. J., O'Sullivan, D., Atkinsona, J. D., and Webbb, M. E.: Ice nucleation by particles immersed in supercooled cloud droplet, Chem. Soc. Rev., 41, 6519-6554, 2012.

Neiman, P. J., Ralph, F. M., Wick, G. A., Lundquist, J. D., and Dettinger, M. D.: Meteorological characteristics and overland precipitation impacts of atmospheric rivers affecting the West Coast of North America based on eight years of SSM/I satellite observations, J. Hydrometeor., 9, 22-47, 2008a.

Neiman, P. J., Ralph, F. M., Wick, G. A., Kuo, Y.-H., Wee, T.-K., Ma, Z., Taylor, G. H., and Dettinger, M. D.: Diagnosis of an intense atmospheric river impacting the Pacific Northwest: Storm summary and offshore vertical structure observed with COSMIC satellite retrievals, Mon. Weather Rev., 136, 4398-4420, 2008 b.

Neiman, P. J., Sukovich, E. M., Ralph, F. M., and Hughes, M.: A Seven-Year Wind Profiler-Based Climatology of the Windward Barrier Jet along California's Northern Sierra Nevada, Mon. Weather Rev., 138, 1206-1233, 2010.

Niemand, M., Mohler, O., Vogel, B., Vogel, H., Hoose, C., Connolly, P., Klein, H., Bingemer, H., DeMott, P. J., Skrotzki, J., and Leisner, T.: A Particle-Surface-Area-Based Parameterization of Immersion Freezing on Desert Dust Particles, J. Atmos. Sci., 69, 3077-3091, doi:10.1175/JAS-D-11-0249.1, 2012. 
Phillips, V. T. J., DeMott, P. J., Andronache, C., Pratt, K., Prather, K. A., R. Subramanian, and C. Twohy: Improvements to an Empirical Parameterization of Heterogeneous Ice Nucleation and its Comparison with Observations, J. Atmos. Sci., 70, 378-409, 2013.

Pratt, K. A., P. J. DeMott, J. R. French, Z. Wang, D. L. W., Heymsfield, A. J., Twohy, C. H., Prenni, A. J., and Prather, K. A.: In situ detection of biological particles in cloud ice crystals, Nat. Geosci., 2, 398-401, doi:10.1038/ngeo521, 2009.

Rosenfeld, D. and Givati, A.: Evidence of orographic precipitation suppression by air pollution-induced aerosols in the western United States, J. Appl. Meteorol. Climatol., 45, 893-911, doi:10.1175/JAM2380.1., 2006.

Rosenfeld, D., Lohmann, U., Raga, G. B., O’Dowd, C. D., Kulmala, M., Fuzzi, S., Reissell, A., and Andreae, M. O.: Flood or drought: How do aerosols affect precipitation?, Science, 321, 1309-1313, doi:10.1126/science.1160606, 2008.

Rosenfeld, D., Chemke, R., DeMott, P., Sullivan, R. C., Rasmussen, R., McDonough, F., Comstock, J., Schmid, B., Tomlinson, J., Jonsson, H., Suski, K., Cazorla, A., and Prather, K.: The common occurrence of highly supercooled drizzle and rain near the coastal regions of the western United States, J. Geophys. Res. Atmos., 118, 9819-9833, doi:10.1002/jgrd.50529, 2013.

Rosenfeld, D., Chemke, R., Prather, K., Suski, K., Comstock, J., Schmid, B., Tomlinson, J., and Jonsson, H.: Polluting of Winter Convective Clouds upon transition from ocean inland OverCentral California: Contrasting Case Studies, Atmos. Res., 135-136, 112-127, doi:10.1016/j.atmosres.2013.09.006,135136, 2014.

Saleeby, S. M., Cotton, W. R., Lowenthal, D., Borys, R. D., and Wetzel, M. A.: Influence of cloud condensation nuclei on orographic snowfall, J. Appl. Meteorol. Climatol., 48, 903-922, doi:10.1175/2008JAMC1989.1, 2009.

Saleeby, S. M., Cotton, W. R., Lowenthal, D., and Messina, J.: Aerosol Impacts on the Microphysical Growth Processes of Orographic Snowfall, J. Appl. Meteorol. Climatol., 52, 834-850, 2013.

Sassen, K.: Indirect climate forcing over the western US from Asian dust storms, Geophys. Res. Lett., 29, 1465, doi:10.1029/2001GL014051, 2002.

Shen, X., Wang, Y., Zhang, N., and Li, X.: Precipitation and cloud statistics in the deep tropical convective regime, J. Geophys. Res., 115, D24205, doi:10.1029/2010JD014481, 2010.

Skamarock, W. C., Klemp, J. B., Dudhia, J., Gill, D. O., Barker, D. M., Wang, W., and Powers, J. G.: A description of the advanced research WRF version 2, NCAR Tech. Note NCAR/TN468+STR, 88 pp., Natl. Cent. for Atmos. Res., Boulder, CO, USA, 2005.
Stith, J. L., Ramanathan, V., Cooper, W. A., Roberts, G., DeMott, P. J., Carmichael, G., Hatch, C. D., Adhikary, B., Twohy, C. H., Rogers, D. C., Baumgardner, D., Prenni, A. J., Campos, T., Gao, R. S., Anderson, J., and Feng, Y.: An overview of aircraft observations from the Pacific Dust Experiment campaign, J. Geophys. Res., 114, D05207, doi:10.1029/2008JD010924, 2009.

Sullivan, R. C., Miñambres, L., DeMott, P. J., Prenni, A. J., Carrico, C. M., Levin, E. J. T., and Kreidenweis, S. M.: Chemical processing does not always impair heterogeneous ice nucleation of mineral dust particles, Geophys. Res. Lett., 37, L24805, doi:10.1029/2010GL045540, 2010.

Tao, W.-K., Chen, J.-P., Li, Z., Wang, C., and Zhang, C.: Impact of aerosols on convective clouds and precipitation, Rev. Geophys., 50, RG2001, doi:10.1029/2011RG000369, 2012.

Tobo, Y., Prenni, A. J., DeMott, P. J., Huffman, J. A., McCluskey, C. S., Tian, G., Pöhlker, C., Pöschl, U., and Kreidenweis, S. M.: Biological aerosol particles as a key determinant of ice nuclei populations in a forest ecosystem. J. Geophys. Res. -Atmos., 118, 10100-10110, doi:10.1002/jgrd.50801, 2013.

Uno, I., Eguchi, K., Yumimoto, K., Takemura, T., Shimizu, A., Uematsu, M., Liu, Z., Wang, Z., Hara, Y., and Sugimoto, N.: Asian dust transported one full circuit around the globe, Nat. Geosci., 2, 557-560, doi:10.1038/ngeo583, 2009.

VanCuren, R. A., Cahill, T. A.: Asian aerosols in North America: Frequency and concentration of fine dust, J. Geophys. Res., 107, 4804, doi:10.1029/2002JD002204, 2002.

van den Heever, S. C., Carrio, G. G., Cotton, W. R., DeMott, P. J., and Prenni, A. J.: Impacts of nucleating aerosol on Florida storms. Part I: Mesoscale simulations, J. Atmos. Sci., 63, 17521775, 2006.

White, A. B., Jordan, J. R., Martner, B. E., Ralph, F. M., and Bartram, B. W.: Extending the dynamic range of an S-band radar for cloud and precipitation studies, J. Atmos. Ocean. Technol., 17, 1226-1234, doi:10.1175/1520-0426(2000)017, 2000.

White, A. B., Neiman, P. J., Ralph, F. M., Kingsmill, D. E., and Persson, P. O. G.: Coastal Orographic Rainfall Processes Observed by Radar during the California Land-Falling Jets Experiment, J. Hydrometeorol., 4, 264-282, 2003.

Yamashita, M., Murakami, M., Hashimoto, A., and Tajiri, T.: CCN Ability of Asian Mineral Dust Particles and Their Effects on Cloud Droplet Formation, J. Meteorol. Soc. Jpn., 89, 581-587, doi:10.2151/jmsj.2011-512, 2011.

Young, K. C.: A numerical simulation of wintertime, orographic precipitation. Part I: Description of model microphysics and numerical techniques, J. Atmos. Sci., 31, 1735-1748, 1974. 